\title{
Artemisinin Improved Neuronal Functions in Alzheimer's Disease Animal Model 3xtg Mice and Neuronal Cells via Stimulating the ERK/CREB Signaling Pathway
}

\author{
Xia Zhao, Shuai Li, Uma Gaur, Wenhua Zheng* \\ Center of Reproduction, Development \& Aging and Institute of Translation Medicine, Faculty of Health \\ Sciences, University of Macau, Taipa, Macau, China
}

[Received April 7, 2019; Revised June 27, 2019; Accepted August 13, 2019]

\begin{abstract}
The most common form of dementia is Alzheimer's disease which is characterized by memory loss and cognitive disorders. The pathogenesis of Alzheimer's disease is not known at present but toxicity of amyloidbeta is one of the central hypotheses. Amyloid-beta can stimulate the production of reactive oxygen species (ROS), cause oxidative stress, damage mitochondrial, cause inflammatory reactions and activate apoptosis related factors which lead to the neuronal death. In this study, we found that artemisinin, a first line antimalarial drug used in clinic for decades, improved the cognitive functions in Alzheimer's disease animal model 3xTg mice. Further study showed that artemisinin reduced the deposition of amyloid-beta and tau protein, reduced the release of inflammation factors and apoptosis factors, and thereby reduced the neuronal cell death. Western blot assay showed that artemisinin stimulated the activation of ERK/CREB signaling pathway. Consistent with these results, artemisinin concentration-dependently promoted the survival of SH-SY5Y cell against toxicity of amyloid-beta protein 1-42 induced ROS accumulation, caspase activation and apoptosis. Artemisinin also stimulated the phosphorylation of ERK1/2 and CREB in SH-SY5Y cells in time and concentration-dependent manner. Inhibition of ERK/CREB pathway attenuated the protective effect of artemisinin. These data put together suggested that artemisinin has the potential to protect neuronal cells in vitro as well as in vivo animal model 3xTg mice via, at least in part, the activation of the ERK/CREB pathway. Our findings also strongly support the potential of artemisinin as a new multi-target drug that can be used for preventing and treating the Alzheimer's disease.
\end{abstract}

Key words: Alzheimer's disease, Artemisinin, cognitive behavior, amyloid beta, $3 \times \mathrm{Tg}$ mice, $\mathrm{SH}-\mathrm{SY} 5 \mathrm{Ycells}$

\begin{abstract}
Alzheimer's disease (AD) is the most widely occurring neurodegenerative disorder which is characterized by loss of memory and behavior disorders $[1,2]$. According to the recent statistics, there are more than 44 million dementia patients worldwide in 2017 and the number will rise to 131.5 million by 2050 , which will cause a serious social and economic burden. Deposition of amyloid plaques, neurofibrillary tangles (NFTs) and the neuronal loss are the three hall markers of $\mathrm{AD}$ [3-7]. In addition,
\end{abstract}

oxidative stress, inflammation, mitochondria dysfunction and increased cholesterol levels are all mechanisms that have been associated with Alzheimer's disease [8, 9]. Among them deposition of $\beta$-amyloid is believed to be the principal component of senile plaques which are responsible for neuronal death and symptom of $\mathrm{AD}$. $\beta$ amyloid is produced by hydrolysis of amyloid precursor protein (APP) by $\beta$-secretase and $\gamma$-secretase. Studies have found that $\beta$-amyloid can stimulate the production of

*Correspondence should be addressed to: Dr. Wenhua Zheng, Faculty of Health Sciences, University of Macau Avenida de Universidade, Taipa, Macau. China. Email: wenhuazheng@um.edu.mo.

Copyright: ( 2019 Zhao X et al. This is an open-access article distributed under the terms of the Creative Commons Attribution License, which permits unrestricted use, distribution, and reproduction in any medium, provided the original author and source are credited. 
reactive oxygen species (ROS), cause oxidative stress, damage mitochondrial, and activate apoptosis-related proteins and factors which lead to the neuronal death $[10$, 11]. In addition, $A \beta$ can also cause neuronal apoptosis by causing inflammatory reactions and neurofibrillary tangles in the brain, which is an important cause of $\mathrm{AD}$ formation and development [12, 13]. So far, neuroprotective strategies based on the amyloid hypothesis are still the central topic of research. In the amyloid hypothesis, the continuous production and reduced clearance of $A \beta$ in neurons lead to the accumulation of these toxic peptides which ultimately leads to a series of pathological events in the process of AD. Many reports suggest that aggregation of $A \beta$ oligomers and fibrils induce the neurotoxicity and lead to the neurodegeneration [14, 15]. Neuronal death and synaptic damage during $\mathrm{AD}$ induced by $\mathrm{A} \beta$ caused the dysfunction of different types of neurons such as cholinergic neurons and also lead to the cognitive deficits [16].

Current treatments are majorly symptomatic utilizing cholinesterase inhibitors such as rivastigmine, galantamine, and donepezil [17]. At moderate as well as severe stages another drug which ismemantine, an $\mathrm{N}$ Methyl-Daspartate receptor antagonist, is also used for AD treatment $[18,19]$. However, the effects of current treatments are far from satisfactory and there is no effective treatment for $\mathrm{AD}$ at present. Defects in the past approaches of treating $\mathrm{AD}$ are: unacceptable toxicity and side effect; single drugs act on single mechanism; treating late stage disease. Therefore, finding multi-target drugs may be an effective strategy for the treatment of AD.

Artemisinin (ART) is extracted from the plant Artemisia annua. It is a very effective anti-malarial drug which is used for the treatment of malaria in clinics for decades and saved millions of malaria patients worldwide [20,21]. ART can pass the blood-brain barrier (BBB) with no observable side effects. In addition, artemisinin has shown to have antioxidant, anti-inflammatory, anti-viral and anti-bacterial effects which exhibit a variety of beneficial pharmacological effects outside of the nervous systems [23]. More important is that we have recently shown that artemisinin has significant neuroprotective effects, which have not been explored yet [22-23, 35]. There is little research on the protective effect of artemisinin on the diseases of the central nervous system (CNS), especially on $\mathrm{AD}$, although artemisinin was suggested to extenuate amyloidogenesis by antiinflammation [24]. Moreover, the therapeutic effects of artemisinin on $\mathrm{AD}$ and the underlying mechanisms are still very elusive.

Transgenic animal models of AD are important tools to further study and evaluate the effect of new chemical/drug on AD. Many animal models of AD have been developed, among which $3 \times \mathrm{Tg}$ mice is the best model that closely mimic the feature of AD. $3 \times$ Tg mouse is a triple transgenic mouse having mutant forms of $\mathrm{APP}_{\text {Swe }}, \mathrm{Tau}_{\mathrm{P} 301 \mathrm{~L}}$ and PS1 $1_{\mathrm{M} 146 \mathrm{~V}}$. The time-course pattern of the region in which neuropathology occurs in $3 x \mathrm{Tg}$ mice closely mimics AD-related changes [25-27]. Longterm memory dysfunction began to appear at 4 months of age. At 6 months of age, the level of oxidative stress is significantly increased, extracellular amyloid deposition occurred, and short-term memory function was impaired. Key enzymes of mitochondrial oxidative phosphorylation showed significant decrease in activity at 9 months of age. At 12 months of age, mitochondrial respiratory efficiency decreased significantly, and obvious amyloid deposition and conformational changes of Tau protein appeared in the cortex and hippocampus [28-31]. Compared to other mice models, $3 \times \mathrm{xg}$ mouse is the best models that closely mimic the features of $\mathrm{AD}$. It helps to clarify the relationship between amyloid, neurofibrillary tangles, neuroinflammation in the same model and is the best model for studying multi-target drugs. Therefore, $3 \times \mathrm{xTg}$ mice could be an ideal model to study $\mathrm{AD}$ and its underlying mechanisms.

In this study, we found that ART significantly improved the cognitive ability, improved neuronal functions by reducing oxidative stress and release of inflammatorily factors and apoptosis-related proteins and factors in $3 \times \mathrm{Tg}$ mice. In addition, ART reduced the deposition of $A \beta$ plaques and neurofibrillary tangles in $3 x T g$ mice. Finally, ART reversed the phosphorylation of ERK/CREB in 3xTg AD mice brain. Experiments using SH-SY5Y also indicated that ART promoted the survival of neuronal cells against $A \beta$ induced impairment via the ERK/CREB pathway. All these findings support that ART can be act via multiple targets and can be used as a potential drug for the prevention and treatment of $\mathrm{AD}$.

\section{MATERIALS AND METHODS}

\section{Reagents and chemicals}

Analytical grade artemisinin was purchased from Meilunbio (Dalian China). Dimethyl sulfoxide (DMSO) and sucrose were procured from Sigma-Aldrich (St. Louis, MO, USA). Hoechst 33258, 5,5',6,6'-tetrachloro1,1',3,3'-tetraethyl-benzimidazolyl-carbocyanineiodide (JC-1), and Poly-D-lysine, 3-(4,5-Dimethylthiazol-2-yl)2,5-diphenyltetrazolium bromide (MTT), were obtained from Molecular Probes (Eugene, OR, USA). CellROX Deep Red Reagent was ordered from Thermo Fisher Scientific (Rockford, IL, USA). DCFH-DA reagent was ordered from Beyotime Institute of Biotechnology (Shanghai, China). Annexin V-FITC/PI Apoptosis 
Detection Kit was obtained from BD Biosciences (San Diego, CA, USA). Trypsin $(0.25 \%)$ and fetal bovine serum (FBS) and $0.25 \%$ were procured from Life Technologies (Grand Island, NY, USA). MEK/ERK inhibitor PD98059 was ordered from Calbiochem (San Diego, CA, USA). The information of antibodies was shown in Table 1 . The detail information of $\beta$-Amyloid (1-42) was provided in Table 2

Table 1. Antibody Information.

\begin{tabular}{lclc}
\hline Antibody & Cat. NO & Source & Company \\
\hline APP/B-Amyloid (NAB228) & 2450 & Mouse & CST \\
$\beta$-Amyloid (1-42 Specific) (D3E10) & 12843 & Rabbit & CST \\
Tau (Tau46) & 4019 & Mouse & CST \\
Phospho-Tau (Ser396) & 11102 & Rabbit & SAB \\
phospho- Tau (thr212) & 1343547 & Rabbit & CALHIOCHEM \\
Phospho- Erk1/2 (Thr202/Tyr204) & $9101 \mathrm{~S}$ & Rabbit & CST \\
ERK 1/2 Polyclonal & 40902 & Rabbit & SAB \\
BAX & $34260-2$ & Rabbit & SAB \\
Bcl-2 & 32012 & Rabbit & SAB \\
Cleaved-Caspase3 & 9661 & Rabbit & CST \\
Cleaved-Caspase9 & 7327 & Rabbit & CST \\
Caspase-1 & $2225 \mathrm{~s}$ & Rabbit & CST \\
Caspase-3 & 9662 & Rabbit & CST \\
Caspase9 & 9508 & mouse & CST \\
Cytochrome c (136F3) & 4280 & Rabbit & CST \\
GFAP (GA5) & 3670 & Mouse & CST \\
IL-1beta (3A6) & $12242 s$ & Mouse & CST \\
Pro-IL-1 $\beta$ Polyclonal Antibody & 41059 & Rabbit & SAB \\
Phospho-CREB (Ser133) (87G3) & 9191 & Rabbit & CST \\
Phospho-c-Jun (Ser73) & 9164 & Rabbit & CST \\
AIF(Iba1) & 38603 & Rabbit & SAB \\
\hline SAB Signalway antibody) & & &
\end{tabular}

\section{Animal and treatment}

The homozygous $3 \times \mathrm{Tg} \mathrm{AD}$ mice $\left(\mathrm{APP}_{\mathrm{Swe}}\right.$, TauP301 L and PS1M146V transgenes) was bought from the Jackson Laboratory and retained in the Animal Facility of University of Macau. All animal experiments were performed in accordance with guidelines accepted by the University of Macau Animal Ethics Committee (protocol No.:UMAEC-13-2015) [16]. The animal housing conditions were regulated (temperature $23{ }^{\circ} \mathrm{C}$; humidity 60-65\%; light from 7:00 to 19:00), and water and food were readily accessible.

$3 \times \mathrm{Tg}$ mice (12 month old, male $\mathrm{n}=6$, weight $32-35 \mathrm{~g}$ ) were randomly segregated in five groups: Control (WT mice+ PBS), 3xTg (3xTg mice+ PBS), $3 \times \mathrm{Tg}+1 \mathrm{mg} / \mathrm{kg}$ ART, $3 x T g+5 \mathrm{mg} / \mathrm{kg}$ ART, $3 \times \mathrm{xg}+10 \mathrm{mg} / \mathrm{kg}$ ART. ART was dissolved in $2 \%$ DMSO in PBS. For one month all the groups were treated with corresponding solutions everyday by intraperitoneal injection.

\section{Morris water maze (MWM)}

The Morris water maze (MWM) test is the classic behavioral experiment which tests the learning and memory ability [32]. The MWM was procured from ZS Dichuang (Beijing, China) having a xeye Aba video tracking system. The MWM is a circular pool $(120 \mathrm{~cm}$ in diameter and $60 \mathrm{~cm}$ in height with white bottom and wall), $1 \mathrm{~cm}$ under the water surface, a white circular platform (diameter $8 \mathrm{~cm}$; height $30 \mathrm{~cm}$ ) was submerged. Foodgrade titanium dioxide ( $100 \mathrm{~g}$ ) was added into the tank to whiten the water so that the mice cannot visually recognize the platform. And the temperature was maintained at $25{ }^{\circ} \mathrm{C}$. On each side of the wall of the quadrants distinct colored papers were placed as visual positional hint. The video tracking camera was staged onto the ceiling directly above the center of the pool to monitor subject swimming parameters [32].

For every training session, the mice were released to the maze back to back from four random points of the tank 
and were permitted to look for the platform for $60 \mathrm{~s}$. In case when the mice did not find the platform within $60 \mathrm{~s}$, they were securely directed to it. The time and movement route of the mice to find the platform were recorded. Mice were kept in a drying cage with a heating system during the test interval. The above operation was repeated for the 2nd, 3rd, 4th, and 5th day. The average latency in the 5day navigational experiments of each group of mice was measured as an indicator for judging the learning ability of mice. On the 6th day, the platform was removed from the water maze, and the mice were allowed to swim freely for $60 \mathrm{~s}$ for space exploration experiments. The number of crossings of the platform, and the residence duration of each mouse in each quadrant of the platform were recorded.

Table 2. Detail information of $\beta$-Amyloid (1-42).

\begin{tabular}{ll}
\hline $\begin{array}{l}\text { Sequence } \\
\text { (Three-Letter Code) }\end{array}$ & H - Asp - Ala - Glu - Phe - Arg - His - Asp - Ser - Gly - Tyr - Glu - Val - His - His - Gln - \\
& Lys - Leu - Val - Phe - Phe - Ala - Glu - Asp - Val - Gly - Ser - Asn - Lys - Gly - Ala - Ile \\
& - Ile - Gly - Leu - Met - Val - Gly - Gly - Val - Val - Ile - Ala - OH \\
One Letter Code & DAEFRHDSGYEVHHQKLVFFAEDVGSNKGAIIGLMVGGVVIA \\
\hline $\begin{array}{l}\text { Molecular Formula: } \mathrm{C}_{203} \mathrm{H}_{311} \mathrm{~N}_{55} \mathrm{O}_{60} \mathrm{~S} \\
\text { Relative Molecular Mass: } 4514.10\end{array}$
\end{tabular}

\section{Tissue preparation}

After MWM test, the mice were put under anesthesia with pentobarbital sodium $(50 \mathrm{mg} / \mathrm{kg})$ and the blood was sampled from the eyeballs. Then, 1 xPBS (pH7.4) was transcardially flushed in the mouse. Brains were quickly collected and dissected on ice, and the left hemisphere brain tissue were immersion fixed with $4 \%$ paraformaldehyde overnight, and embedded in paraffin following the standard procedures, which can be stored for a long time [33]. The cortexes of right hemisection were cut open on ice and kept at $-80{ }^{\circ} \mathrm{C}$ for Western blot assay.

\section{Immunohistochemistry and Immunofluorescence}

Immunohistochemistry (IHC) is used to localize/visualize the expression of protein in a mounted tissue section using protein specific antibodies [33]. The brain tissues were sliced into $5 \mu \mathrm{m}$ slices using Manual Rotary Microtome Basic Instrument (Leica RM2235, Leica, Germany). After routine dewaxing hydration, antigen retrieval was carried out by immersing in $0.01 \mathrm{M}$ citrate buffer solution. This was followed by incubation with $3 \% \mathrm{H}_{2} \mathrm{O}_{2}$ for $15 \mathrm{~min}$ to remove endogenous peroxidase activity. After blocking with $10 \%$ bovine serum albumin (BSA) for $1 \mathrm{~h}$, the primary antibody was added dropwise to slices which were stored overnight at $4{ }^{\circ} \mathrm{C}$. Next day, the brain tissue sections were then incubated with second antibody for 60 min and followed by DAB color development.

Immunofluorescence is a method in which a known antibody labeled with fluoresce in is used as a probe to detect a target antigen in a tissue or a cell to be tested, and the formed antigen-antibody complex is provided with fluorescein, and thus can be directly observed by a fluorescence microscope. The brain tissue was embedded in OCT (optimal cutting temperature) compound. The brain was sliced into $20 \mu \mathrm{m}$ slices using a low temperature thermostat (Leica CM3050, Leica, Germany). Each section was washed with 1xPBS for three times and then blocked with $10 \% \mathrm{BSA}$ for $1 \mathrm{~h}$ at room temperature. After that, tissue sections were incubated with primary antibody in PBS containing $1 \% \mathrm{BSA}$ at $4^{\circ} \mathrm{C}$ overnight. The following day, sections were incubated with appropriate secondary antibody for $1 \mathrm{~h}$ at room temperature in the dark. Nuclei were counterstained with DAPI, and the images were acquired with a Nikon A1 confocal microscope.

\section{Congo red staining and Nissl staining}

The embedded brain tissues were cut into $5 \mu \mathrm{m}$ thin slices and followed by dewaxing in xylene and dehydrating by alcohol gradients. After that, sections from each group were stained with Highman Congo red staining solution for 5 to 10 minutes followed by washing three times with water, and then transferred in hematoxylin staining solution for 1 2min, stained for the nucleus. Washed with distilled water, and differentiated and returned to blue. After staining, slices were dehydrated by fractional alcohols, transparent with xylene and mounted with Neutral gum.

Nissl staining was used to detect the surviving neurons. Nissl is large and large in number, indicating that nerve cells synthesize proteins with strong functions; on the contrary, when nerve cells are damaged, the number of Nissl bodies will decrease or even disappear. For each group, sections (each $5 \mu \mathrm{m}$ thick) were stained with Nissl staining solution (C0117, Beyotime, Shanghai, China) for $10 \mathrm{~min}$ at $37-50{ }^{\circ} \mathrm{C}$ and then washed, color separated, dehydrated, hyalinized and mounted. The cells which contained a clear body and nucleus were counted as 
surviving neurons in the sections of hippocampus. The survival index was measured following this formula: survival index $(\%)=($ number of surviving neurons/total number of neurons) $\mathrm{x} 100 \%[34]$.

\section{TUNEL assay}

Cell apoptosis was determined by the TUNEL assay performed using a TUNEL kit (C1098, Beyotime, Shanghai, China) following manufacturer's instructions. Processed samples were incubated in a TUNEL reaction mixture $(50 \mu \mathrm{L})$ for $60 \mathrm{~min}$ at $37^{\circ} \mathrm{C}$ under dark conditions. Color developed in DAB coloring solution. Brown is apoptotic cells positive for TUNEL staining. Apoptosis index in the cortex area was measured using this formula: apoptosis index $(\%)=($ apoptotic neurons/ total neurons) X 100\%。

\section{MTT assay}

MTT assay was used to determine the cell viability [35]. After treatment, the cells were further incubated with MTT $(0.5 \mathrm{mg} / \mathrm{ml})$ for $3-4 \mathrm{~h}$. The medium was removed from each well and $100 \mu 1$ DMSO was added to dissolve the dark-blue formazan crystals that were formed in living cells. The absorbance was measured in each well solution using a microplate reader (SpectraMax 250, Molecular Device, Sunnyvale, CA, USA).

\section{Annexin V-FITC/PI staining for apoptosis evaluation}

Flow cytometry assay was performed following the kit guidelines. Briefly, SH-SY5Y cells were trypsinized after appropriate treatment, rinsed twice with ice-cold PBS, centrifuged at $1000 \mathrm{rpm}$ for $5 \mathrm{~min}$ and re-suspended the cells in Annexin V-FITC/PI binding buffer $(195 \mu \mathrm{L})$. Annexin V-FITC $(5 \mu \mathrm{L})$ was supplemented and the cells were stored in dark at room temperature for $30 \mathrm{~min}$. Cells were then pellet down by centrufing at 1000rpm for $5 \mathrm{~min}$ and re-suspended in Annexin V-FITC/PI binding buffer $(190 \mu \mathrm{L})$; Propidium Iodide (PI) $(10 \mu \mathrm{L})$ was further added, followed by incubation in the dark for 5 mins. The apoptotic cells were quantified using Flow cytometer.

\section{Measurement of intracellular ROS levels}

After appropriate treatment, the SH-SY5Y cells were stored at dark with CellROXs Deep Red Reagent (5 mM) in DMEM (without PBS) for 1h, rinsed twice with 1x PBS solution and the fluorescence was measured and recorded under an Infinite M200 PRO Multimode Microplate at an emission wavelength of $665 \mathrm{~nm}$ and an excitation wavelength of $640 \mathrm{~nm}$.

\section{Measurement of mitochondrial membrane potential $(\Delta \psi m)$}

JC-1 dye was utilized to observe the mitochondrial integrity. In brief, SH-SY5Y cells $\left(6 \times 10^{3}\right.$ cells/well) were seeded in a 96-well plate with $1 \%$ FBS DMEM medium. After suitable treatment, the cells were incubated with $1 \mathrm{x}$ JC-1 $\left(10 \mu \mathrm{g} / \mathrm{ml}\right.$ in blank medium) at $37^{\circ} \mathrm{C}$ for $30 \mathrm{~min}$ and rinsed two times with PBS. For signal quantification, the intensity of red fluorescence (excitation $560 \mathrm{~nm}$, emission $595 \mathrm{~nm}$ ) and green fluorescence (excitation 485nm, emission $535 \mathrm{~nm}$ ) were measured and recorded using an Infinite M200 PRO Multimode Microplate. $\triangle \psi m$ was calculated as the ratio of JC-1 red/green fluorescence intensity and the values were normalized to the control group.

\section{Mitochondrial / Cytosol protein extraction}

Mitochondrial and Cytosol protein were isolated from SH-SY5Y cells and brain tissue using differential centrifugation as described by Ivan Dimauro et al [36]. After we got the supernatant (Cytosol) and pellet (crude mitochondria), the mitochondria was purified by using ultracentrifugation. The crude mitochondrial pellet was resuspended in $50 \mathrm{mM}$ Tris- $\mathrm{HCl}(\mathrm{pH} \mathrm{7.4)}, 250 \mathrm{mM}$ sucrose and protease inhibitors and ultracentrifuge at $100,000 \mathrm{~g}$ for $20 \mathrm{~min}$ at $4^{\circ} \mathrm{C}$. The protein concentration was determined with BCA protein assay kit and analyzed by western blot using anti-cytochrome $\mathrm{C}$ antibody.

\section{Western blot}

The shredded mice brain tissue was blended in RIPA buffer containing protease inhibitors. The tissue sample was disrupted by sonication, and then centrifuged at $12,000 \mathrm{~g}$ for $20 \mathrm{~min}$ at $4{ }^{\circ} \mathrm{C}$, and the supernatants were taken out in separate tubes. Protein concentration of each sample was determined with a BCA Protein Assay [37]. Same amount of proteins was electrophoretically separated using polyacrylamide gel electrophoresis (PAGE) and transferred onto polyvinylidene fluoride (PVDF ) membranes at $200 \mathrm{~mA}$ for $2 \mathrm{~h}$. The PVDF membranes containing protein bands were blocked with $5 \%$ skimmed milk at room temperature for $1 \mathrm{~h}$, and incubated with primary antibodies overnight at $4{ }^{\circ} \mathrm{C}$. Following day, the membranes were incubated with horseradish peroxidase (HRP)-conjugated secondary antibodies (1:2000; CST) for $1 \mathrm{~h}$ at room temperature. The specific protein bands were seen using the Bio-Rad Gel Doc XR documentation system.

\section{Statistical analysis}


All the data was presented as mean \pm SE. Each experiment was carried out in triplicates. For the MWM test, escape latency times in the hidden platform trial were analyzed via two-way ANOVA of repeated measures. Statistical differences were analyzed by one-way ANOVA in combination with post hoc Tukey's test $(\alpha=0.05)$ to assess the difference between any two groups by using GraphPad Prism 5.0 statistical software (GraphPad software, Inc., San Diego, CA, USA). P<0.05, P<0.01 were considered statistically significant.
A

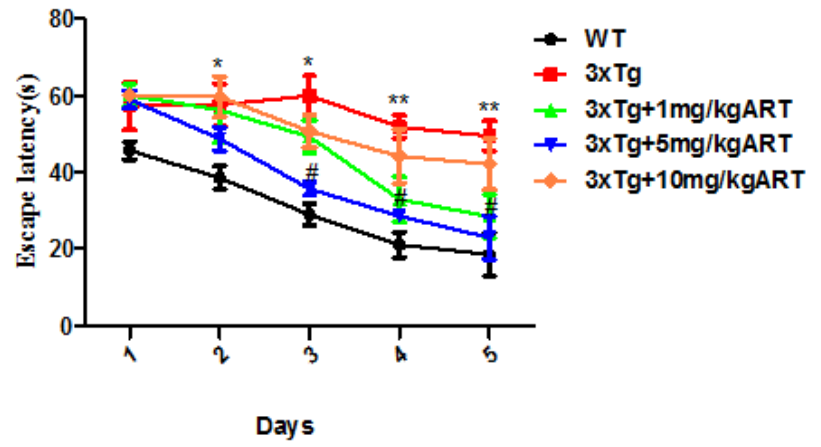

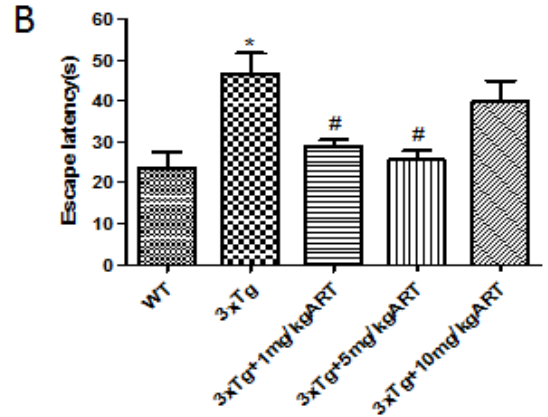

C

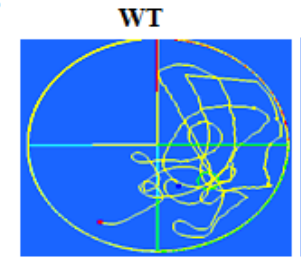

D

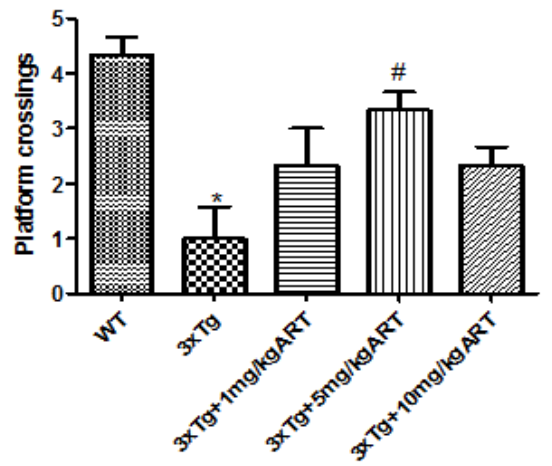

$3 \times T g+1 \mathrm{mg} / \mathrm{kg}$ ART
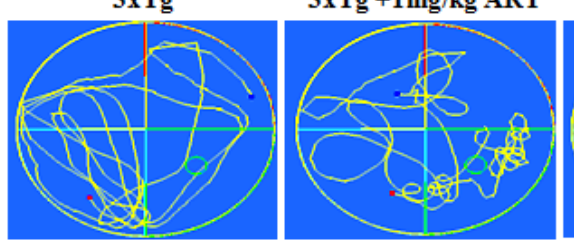

$\mathrm{E}$
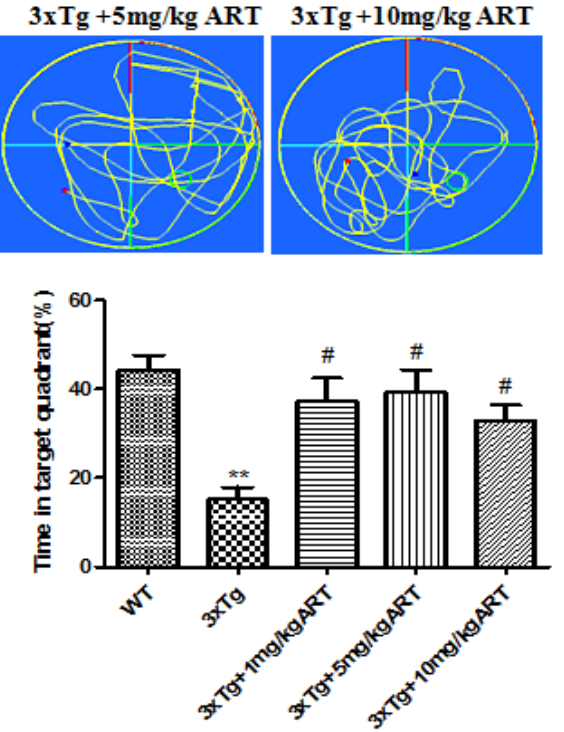

Figure 1. Artemisinin improved the cognitive deficit of aged 3xTg mice. (A) Average escape latencies curve (four trials per day in the five consecutive days). (B) Time needed to find the hidden platform (escape latency) during the training. (C) Representative path tracking in the probe tests without hidden platform in day 6. (D) The average crossing platform times of each group mice within 60s in day 6. (E) Time spent in the target quadrant where the platform had been located in day 6 . * $\mathrm{p}<0.05$ or $* * \mathrm{p}<0.013 \mathrm{xTg}$ vs WT; \#p $<0.053 \times$ Tg vs $3 \times$ Tg+ART.

\section{RESULTS}

\section{Artemisinin improved the cognitive function in $3 x T g$ mice}

In order to study the effect of artemisinin on cognitive functions of 3xTg AD mice, we performed MWM assay. Accordingly, one year aged 3xTg AD mice were divided to five groups and tested as indicated. Our results showed that artemisinin administration for 1 month in $3 \times \mathrm{Tg} \mathrm{AD}$ mice significantly improved their ability to locate the platform on the MWM, and also resulted in enhancement in the spatial learning tasks. The average escape latencies for 5 consecutive days in each group are displayed in curves (Fig. 1A). The average escape latency of $3 \times \mathrm{Tg}+$ $5 \mathrm{mg} / \mathrm{kg}$ ART group was significantly lower than $3 \times \mathrm{Tg}$ group in the 3rd 、 4th and 5th day. Next, for quantificational evaluation (Fig. 1B), the $3 \times T g+1 \mathrm{mg} / \mathrm{kg}$ ART and the $3 x T g+5 \mathrm{mg} / \mathrm{kg}$ ART group mice exhibited a higher retention performance on the learning test in comparison to $3 \times \mathrm{Tg}$ mice. The above results were further reinforced by a subsequent probe trial without the platform in the 6th day. The usual path tracking of each group in $60 \mathrm{~s}$ is displayed in Figure 1C. We computed the platform location crossing times and the percentage of target quadrant search time (Fig. 1D and Fig. 1E), both of 
which demonstrated the memory retention of the location of the hidden platform. The data indicated that there were more platform location crossing times and an increased percentage of target quadrant search time in the
$3 \times \mathrm{Tg}+\mathrm{ART}$ group in comparison of the $3 \times \mathrm{Tg}$ group. These results suggest that artemisinin can enhance the spatial memory capacity in AD mice.
A
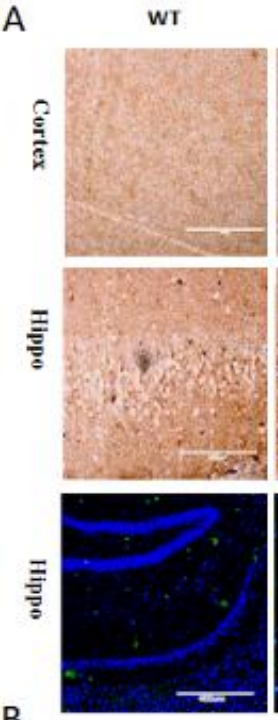

WT
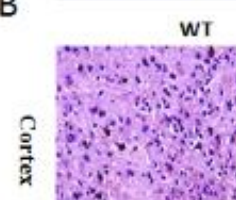
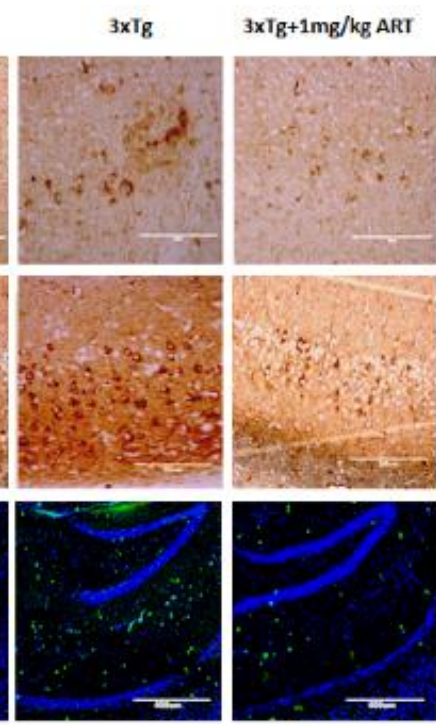

$3 \times T_{g}$
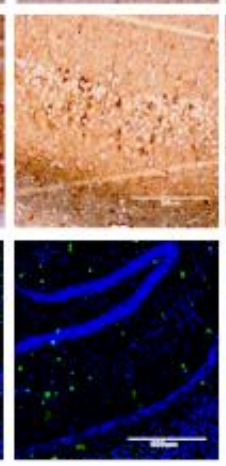

$3 \times T g+1 \mathrm{mg} / \mathrm{kg}$ ART
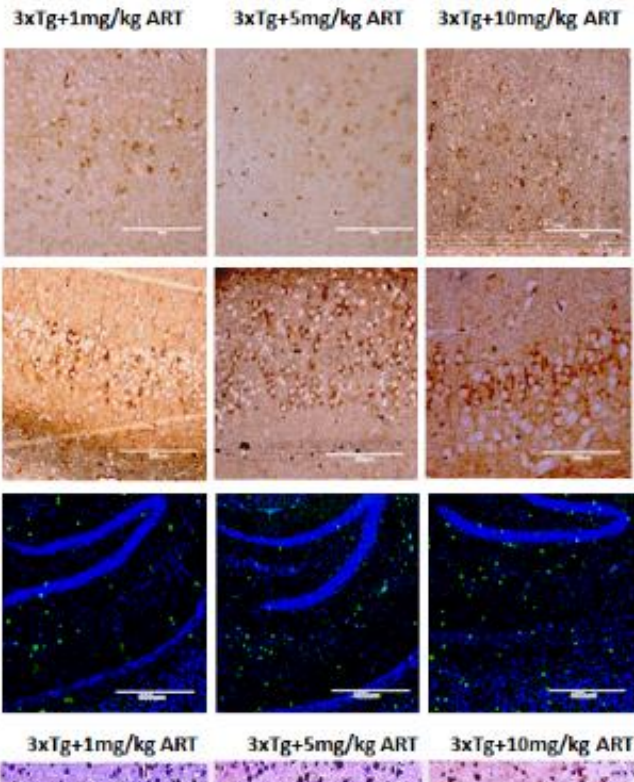

$3 \times 1 \mathrm{~g}+5 \mathrm{mg} / \mathrm{kg}$ ART $\quad 3 \times T \mathrm{~g}+10 \mathrm{mg} / \mathrm{kg}$ ART
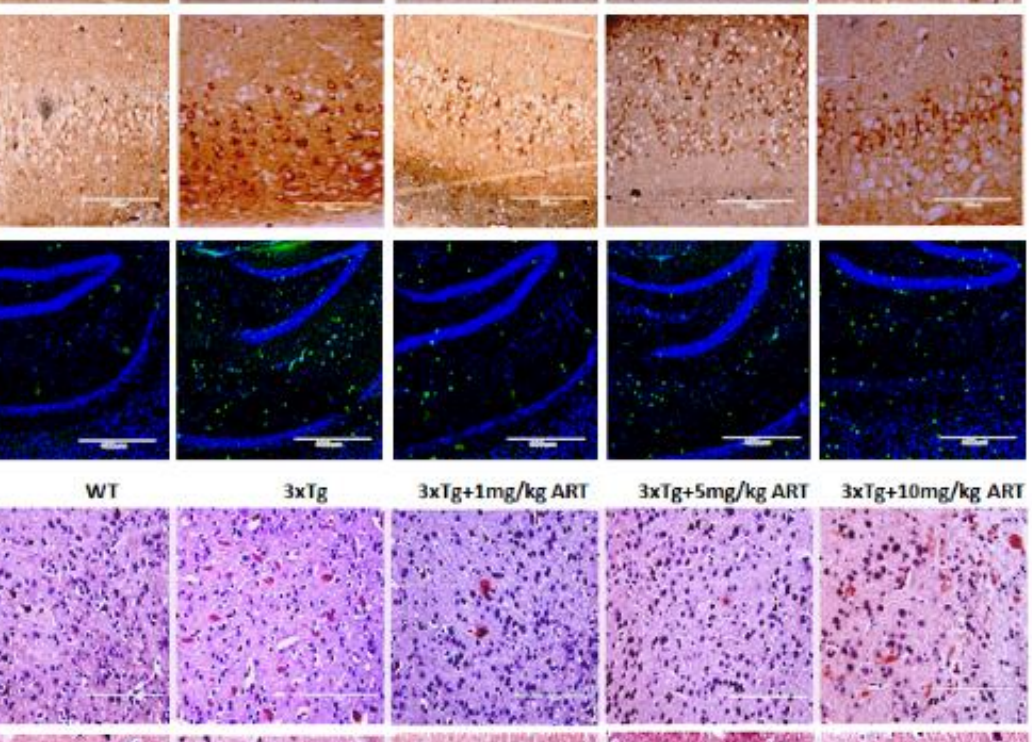

클

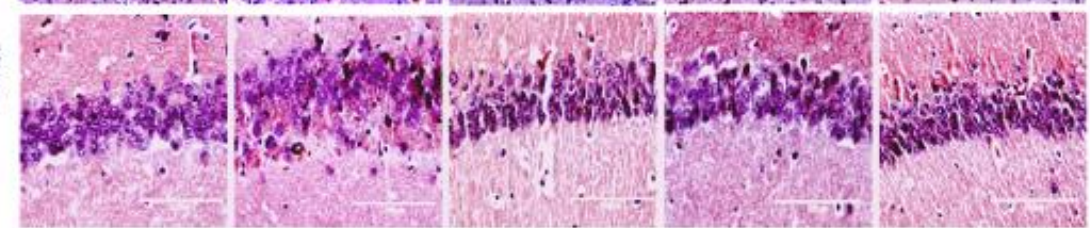

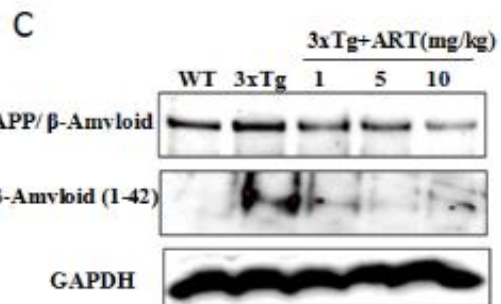

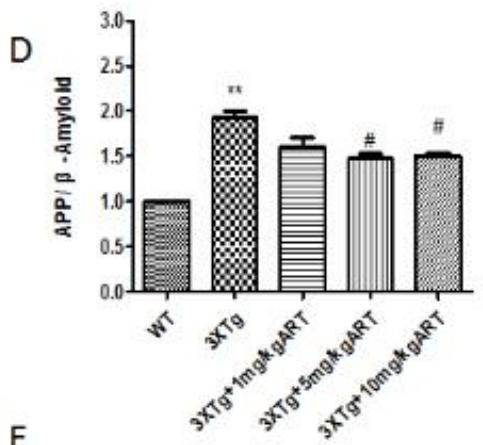

$E$

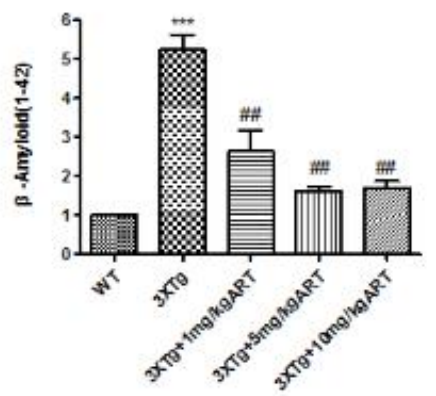

Figure 2. Artemisinin reduced $\mathbf{A} \boldsymbol{\beta}$ deposition in aged 3xTg mice. (A) Immunohistochemistry (20x) and Immunofluorescence (10x) of $\mathrm{A} \beta$ in cortex and hippocampus; (B) Congo red staining (labeled amyloidosis) in cortex and hippocampus(40x); (C) Expression of APP/A $\beta 1-42$ and the short APP fragments A $\beta 1-42$ were determined by Western blot. (D-E) Quantitation of Western blots. ${ }^{*}$ p $<0.013 x T g$ vs WT; ${ }^{p}$ < $<0.05$ or ${ }^{\# \#<p: 0.01 . ~ 3 x T g ~ v s ~} 3 \times T g+A R T$.

\section{Artemisinin reduced the deposition of $A \beta$ and Tau in $3 x$ Tg mice}

The 3xTg mice exhibited strong A $\beta$ deposition, a neuropathological result of $\mathrm{AD}$, in comparison to the WT mice (12 months old). Upon evaluating the effect of ART treatment on $A \beta$ deposition, a significant reduction in extracellular $A \beta$ deposition was seen in all of the examined cerebral regions of the ART $+3 \times \mathrm{Tg}$ mice brain in comparison to $3 \times \mathrm{Tg}$ mice, which further validated the results (Fig. 2A). We got the similar result by Congo-red staining (Fig. 2B). Congo red is used for staining in amyloidosis, the results of Congo red staining showed that there were more $A \beta$ deposits in cortex and hippocampus of $3 \times \mathrm{Tg}$ mice, while the $\mathrm{A} \beta$ deposits in cortex and hippocampus were significantly reduced after treatment with artemisinin. The result was further confirmed by western blot as presented in Figure 2C-E.

The hyperphosphorylation of $\mathrm{Tau}$ is another prominent feature that is responsible for neuronal death during $\mathrm{AD}$ [38]. In order to understand the underlying action mechanism of ART on cognitive improvement, we checked the tau phosphorylation in the 3xTg mice brain by IHC and western blots. As shown in Figure 3A, there was significant reduction in phosphorylated tau levels in the ART treated mice was recorded when compared to $3 \times T g$ mice. The result was confirmed by western blot (Fig. 3B-D). Overall, ART treatment resulted in a reduction in tau phosphorylation. 
A
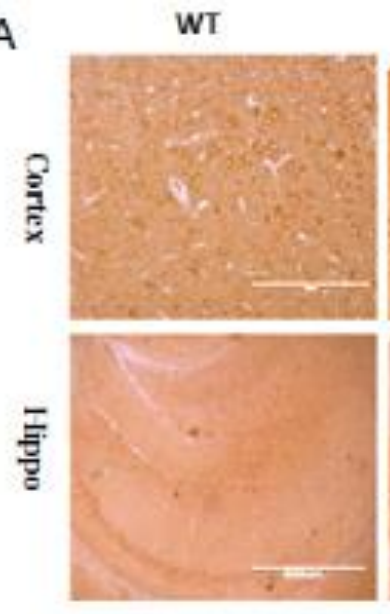

B

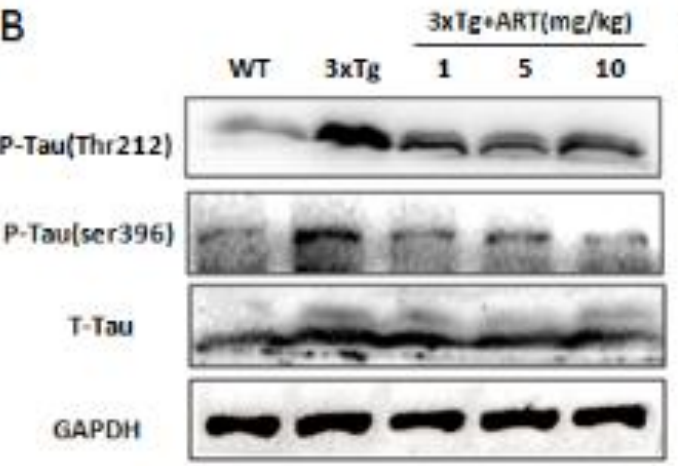

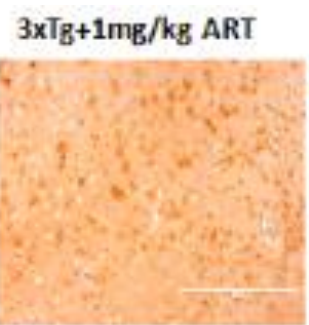
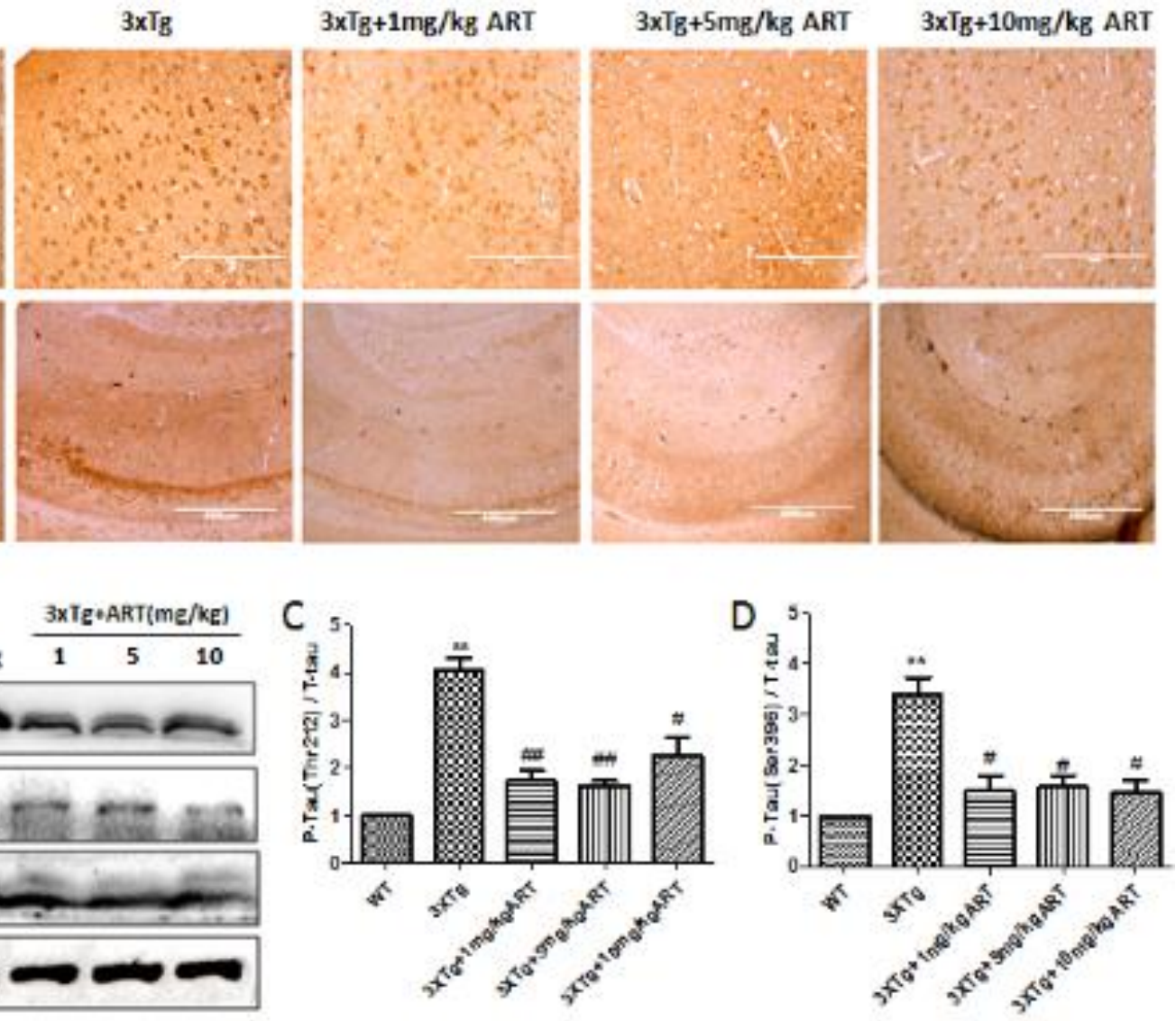

Figure 3. Artemisinin reduced Tau deposition in aged 3xTg mice. (A) Immunohistochemistry (Cortex 20x, hippo10x) of p-Tau in cortex and hippocampus. (B) Expression level of p-Tau was detected by Western blot. (C-D) Quantitation of Western blots in B. $* * \mathrm{p}<0.013 \mathrm{xTg}$ vs WT; ${ }^{\mathrm{p}}<0.05$ or ${ }^{\# \#}<\mathrm{p}: 0.01 .3 \times \mathrm{Tg}$ vs $3 \mathrm{xTg}+\mathrm{ART}$.

\section{Artemisinin attenuated the activation of glial cells and expression of inflammatory molecules in $3 x T g$ mice}

Inflammation is another important pathophysiological feature of $\mathrm{AD}$, accompanied by activation of glial cells and release of inflammatory factors [39, 40]. Overactivated astrocytes cells and microglia cells can stimulate neuroinflammatory reactions. Astrocyte activation is indicated by the emergence of a hypertrophic soma and processes and is often appear with an increase in the expression of GFAP, which is a major intermediate filament protein exclusive to astrocytes $[8,41]$. Therefore, in current study we checked whether the expression of its specific marker GFAP changed in various treatment groups. The data displayed a significant increase in GFAP immunoreactivity in the $3 \times \mathrm{Tg}$ mice in comparison to the WT mice (Fig. 4A). However, ART treatment significantly decreased the GFAP immunoreactivity in cortex area, suggesting that ART may have antiinflammatory effect.

In order to further confirm whether ART reduces inflammation, marker of microglia (Iba1) was also checked (Fig. 4A). Under normal conditions, the morphology of microglia cells is in a branched form, which can secrete growth factors to maintain the survival of neurons. After excessive activation, the branches of microglia shorten or even disappear, and secrete inflammatory factors leading to nerve cell death. From the result we found that ART treatment significantly improved microglia morphology in $3 x \mathrm{Tg}$ mice. In support of these results, ART brought down the levels of the brain inflammatory markers IL- $1 \beta$ and cleaved caspase 1 which were found increased in $3 \times \mathrm{Tg}$ mice by western blot (Fig. 4B-D). The above results suggested that the therapeutic effect of ART in the $3 \times T$ m mice is due to both neuroprotective and anti-inflammatory effects. 
A
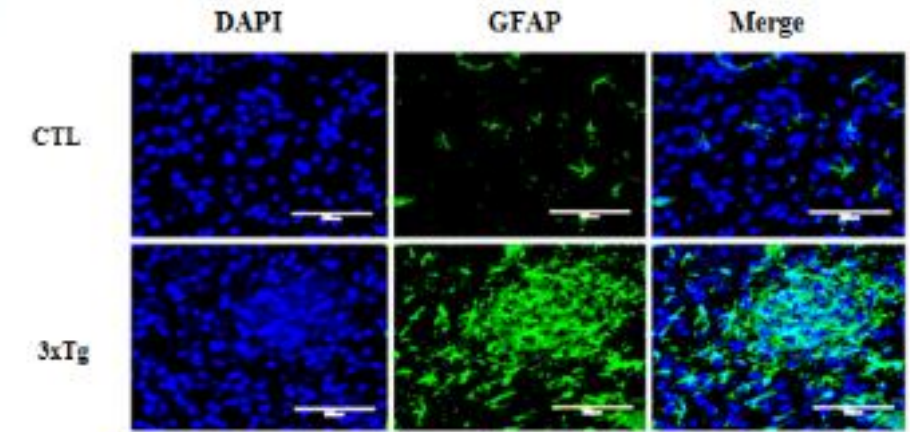

$3 \times T_{E}+1 \mathrm{mg} / \mathrm{kg}$ AR

$3 \times \mathrm{Tg}+5 \mathrm{mg} / \mathrm{kg}$ ART

(n)

$3 \times \mathrm{Te}+10 \mathrm{me} / \mathrm{kg}$ ART

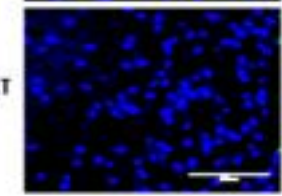

B

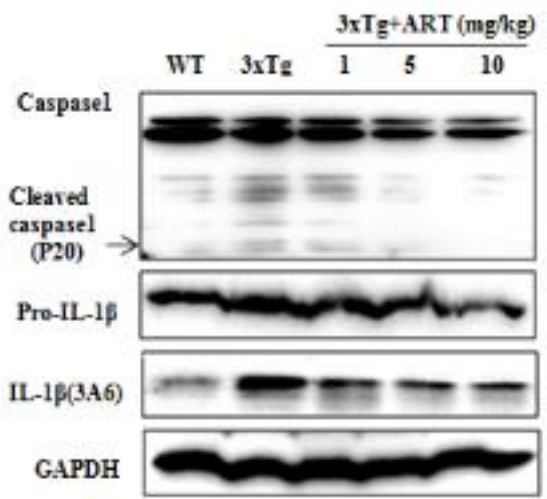

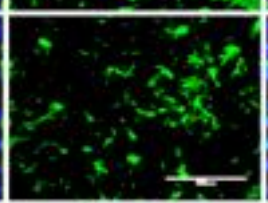
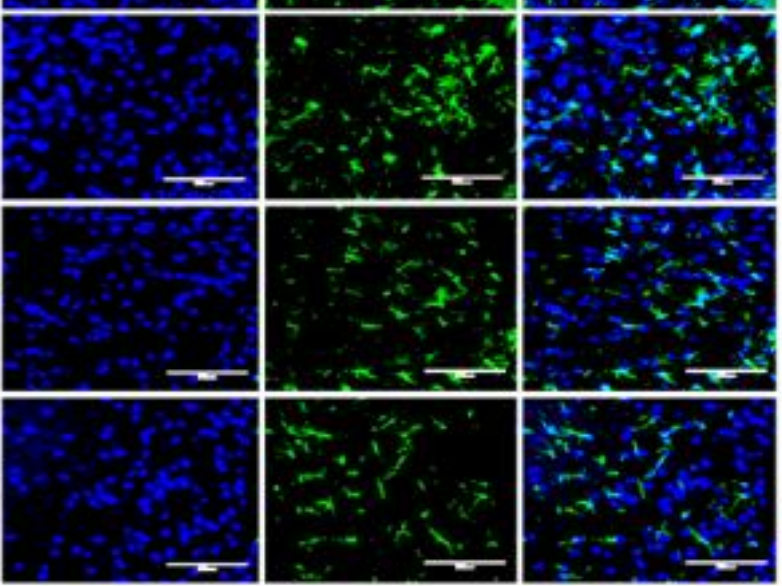

C
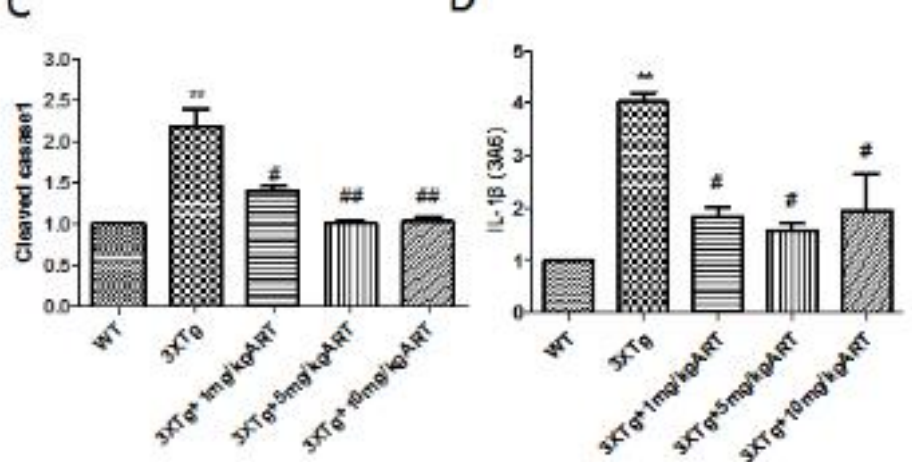

Figure 4. Artemisinin attenuated the activation of glial cells, caspase activation and the expression of inflammatory molecules IL-1 $\beta$ in the brain of aged 3xTg mice. (A) Immunofluorescence and Immunohistochemistry of GFAP (Astrocyte marker) and AIF1 (Iba1, microglia marker) (40x). (B) Western blot analysis of the effect of ART on IL-1 $\beta$ and caspase1.

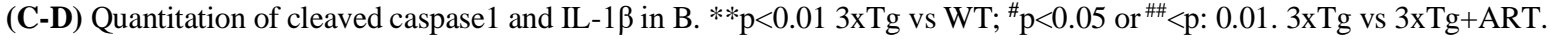

ART attenuated the histopathological changes and decreased neuronal apoptosis in 3xTg mice by activation of ERK

Histopathological changes were recorded in HE-stained images of hippocampus and cortex of mice from WT, $3 \times \mathrm{Tg}$ and $3 \times \mathrm{Tg}+\mathrm{ART}$ groups. The results showed that injured neurons in 3xTg mice were darkly stained and also exhibited vacuolar bodies. Cells were arranged in disorder with slight change and neuron loss was also seen. In contrast, treatment with ART significantly restrained the histopathological damage, improved the vacuolar bodies
(Fig. 5A). When neurons are damaged, Nissl body can get reduced or even disappeared, and the cells get deeply stained with eosin. Nissl staining showed that in the WT group the Nissl bodies were large and numerous, indicating that the protein synthesis activity was stronger in nerve cells, whereas the number of Nissl bodies in $3 \times \mathrm{Tg}$ mice was reduced, the staining was shallow, and the staining was unclear. This condition was improved after ART treatment (Fig. 5B and D). We further observed the effect of ART on brain cortical neuronal apoptosis by TUNEL staining. The number of apoptotic brain cortical neurons was significantly decreased following treatment 
of $3 x T g$ mice with ART, relative to untreated $3 x T g$ mice (Fig. 5C and E).

Studies indicated the involvement of ERK in the inhibition of apoptosis. Here, the expression of p-ERK1/2 and $\mathrm{p}$-CREB was determined to evaluate the treatment effect of ART in 3xTg mice. The expression level of $p$ ERK1/2 and P-CREB was significantly increased in $3 \times \mathrm{Tg}+\mathrm{ART}$ group compared with $3 \mathrm{xTg}$ group (Fig. 5F). We tested the expression of apoptosis regulator in different treatment groups also. The expression levels of
Bax, Bcl-2, Cytochrome C, caspase- 9 and caspase- 3 were detected by western blotting (Fig. 5F). The expression of proapoptotic factors Bax, Cytochrome $\mathrm{C}$, cleavedcaspase- 9 and cleaved caspase- 3 was upregulated while that of Bcl-2 (an inhibitor of apoptotic proteins) was downregulated in $3 \times \mathrm{Tg}$ mice in comparison to the WT group. Treatment with ART increased the ratio of Bcl-2 /Bax compared with the $3 \times \mathrm{Tg}$ group. These results indicated that ART reduced brain neuronal apoptosis may through ERK/p-CREB/Bcl2 axis.
A
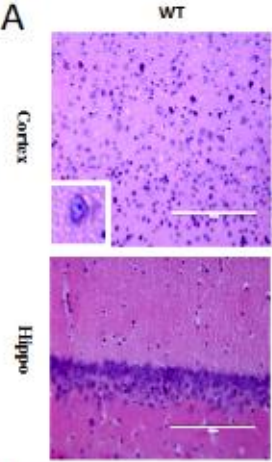

B
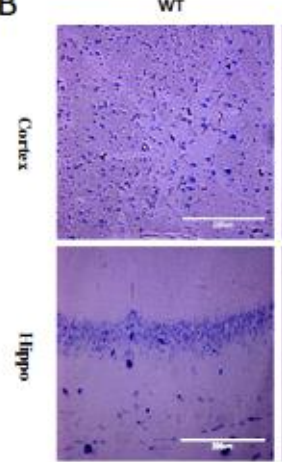

C

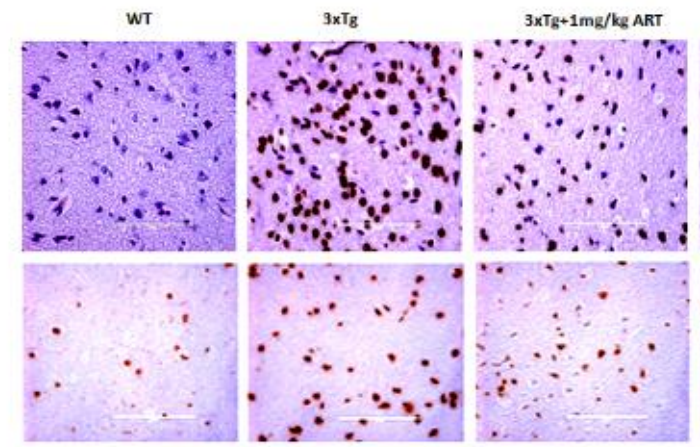

$3 \times \mathrm{Tg}$

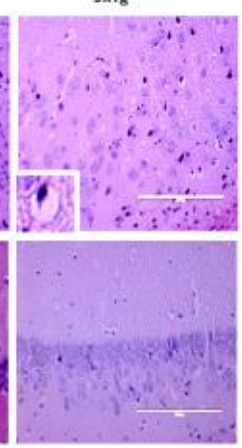

$3 \times \mathrm{Tg}$
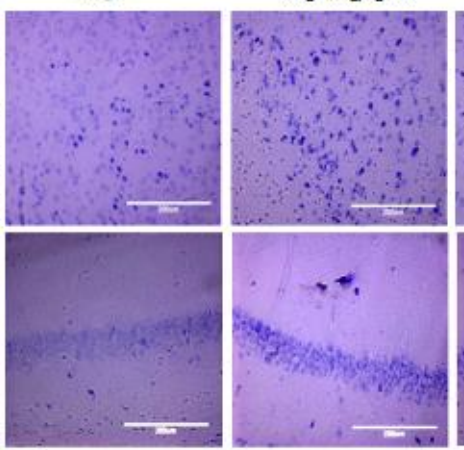
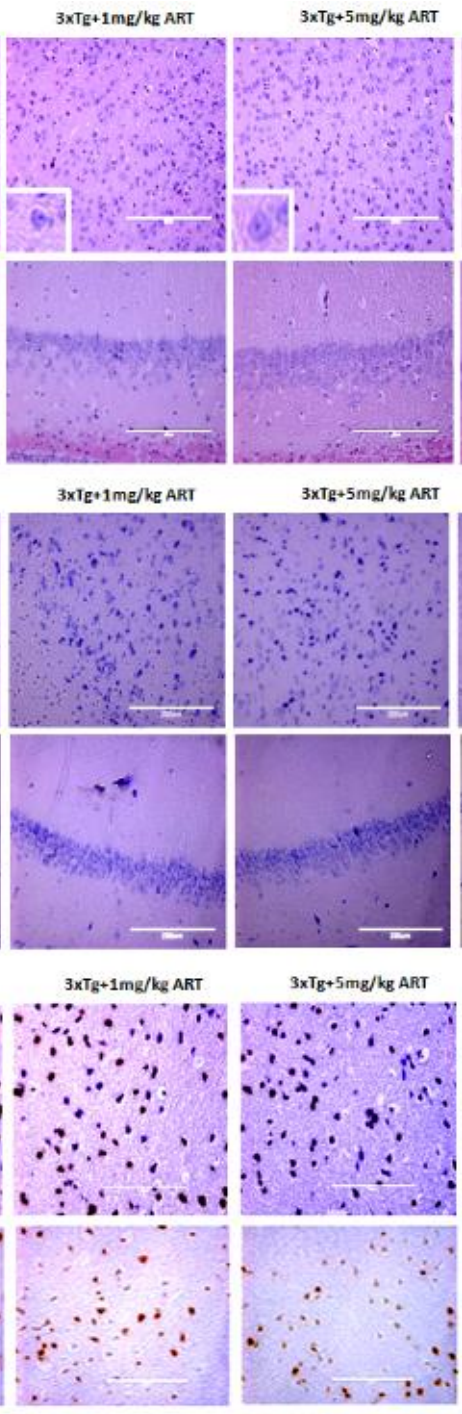

$3 \times \mathrm{Tg}+5 \mathrm{mg} / \mathrm{kg}$ ART
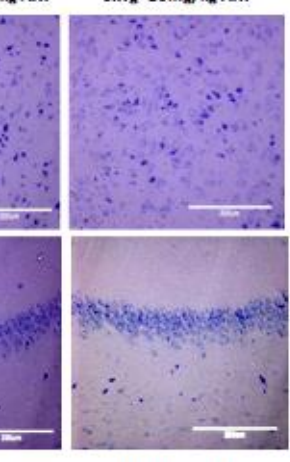

$3 \times \mathrm{T}+10 \mathrm{mg} / \mathrm{kg}$ ART

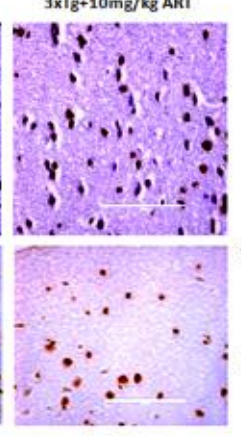

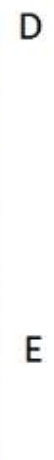
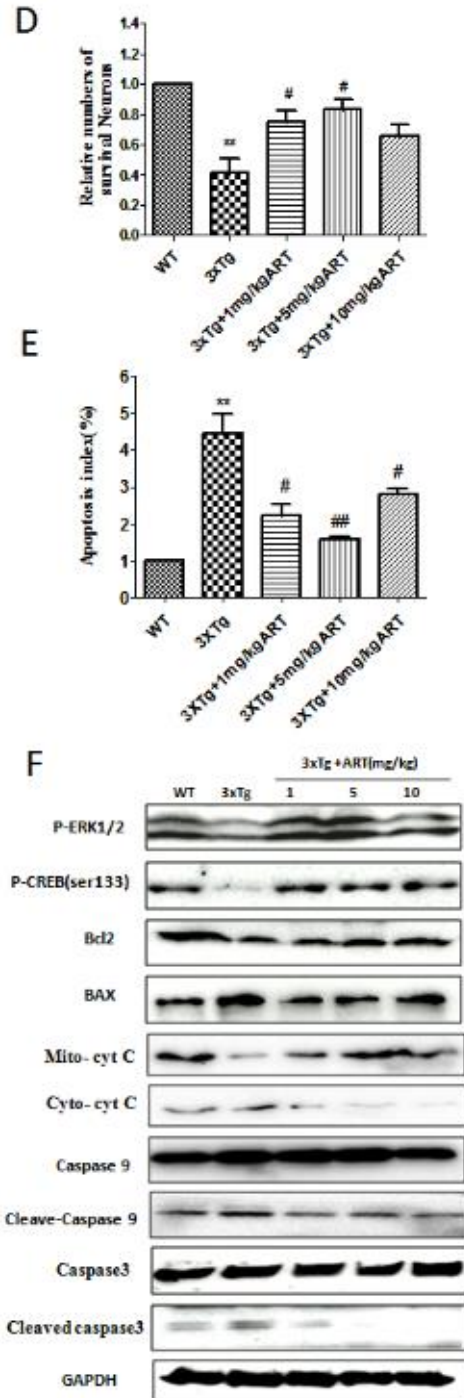

Figure 5. Artemisinin attenuated the histopathological changes and decreased neuronal apoptosis in 3xTg mice by activation of ERK. (A) HE staining showed the histopathological changes of neurons in 3xTg mice (40x). The cells were vacuolated, and ART increased cell number and reduced cell vacuolation; (B) Neuronal cell function was then examined using Nissl staining and our result indicated that artemisinin significantly improved neuronal function of 3xTg mice (40x); (C) Apoptosis determined by TUNEL staining in cortex of wild type and 3xTg mice treated as indicated (40x) . (D) Statistical analysis results of Nissl staining. (E) Quantitation of the deoxynucleotidyl transferased UTP nick-end labeling (TUNEL) staining in C. (F) The expression of p-ERK1/2, p-CREB, Bax, Bcl2, Cytochrome $\mathrm{C}$, cleaved caspase 9 and cleaved caspase-3 (active form of caspase 3 ) and GAPDH were detected by Western blot. $* * \mathrm{p}<0.013 \mathrm{xTg}$ vs WT; ${ }^{\mathrm{p}}<0.05$ or ${ }^{\#}<\mathrm{p}: 0.01 .3 \times \mathrm{Tg}$ vs $3 \mathrm{xTg}+\mathrm{ART}$. 
ART attenuated the cell viability induced by $A \beta_{1-42}$ in SY5Y cells

SH-SY5Y cells were incubated with different concentrations of ART or $A \beta_{1-42}$ for $24 \mathrm{~h}$ and MTT assay was used to determine the cell viability. ART treatment did not induce any cytotoxicity in SH-SY5Y cells up to a concentration of $200 \mu \mathrm{M}$ (Fig. 6B). $\mathrm{A} \beta_{1-42}$ caused significant cytotoxicity in SH-SY5Y cells starting at $2 \mu \mathrm{M}$ in comparison to the control group (Fig. 6C). The cell viability was almost half, so we chose $4 \mu \mathrm{M} \mathrm{A} \beta_{1-42}$ for all of the following experiments. In order to examine the protective effects of ART, SH-SY5Y cells were pretreated with different dose of ART for $2 \mathrm{~h}$ before exposing to $A \beta_{1-}$ ${ }_{42}$ for another $24 \mathrm{~h}$. Results showed that pre-treatment with $12.5 \mu \mathrm{M}$ ART can significant reduce $\mathrm{A} \beta_{1-42}$-induced cell death (Fig. 6D).
A

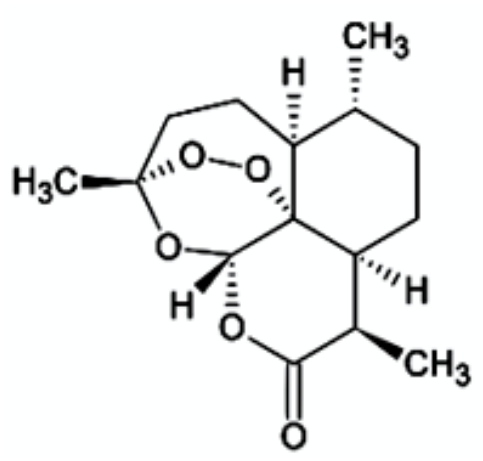

C

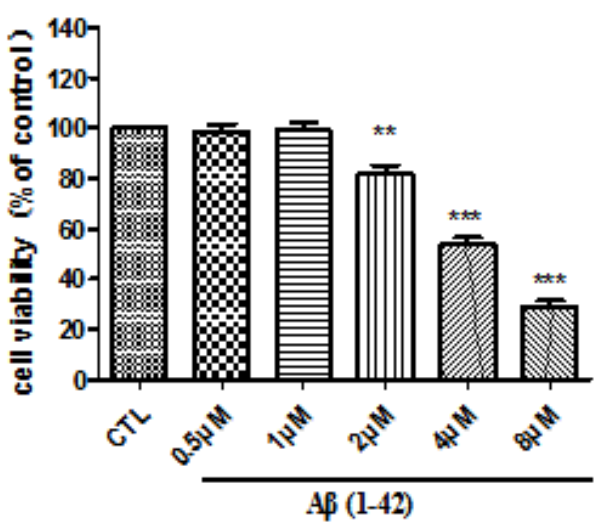

B

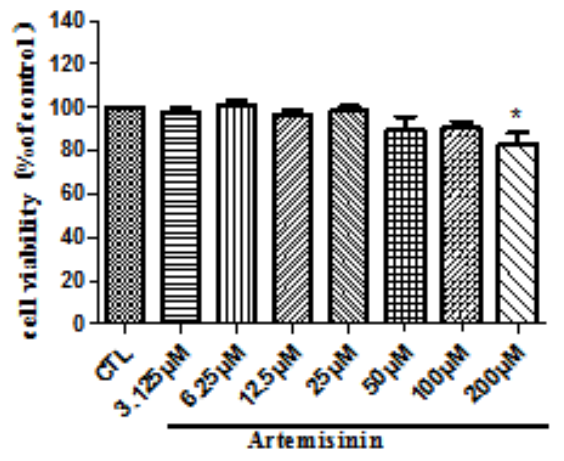

D

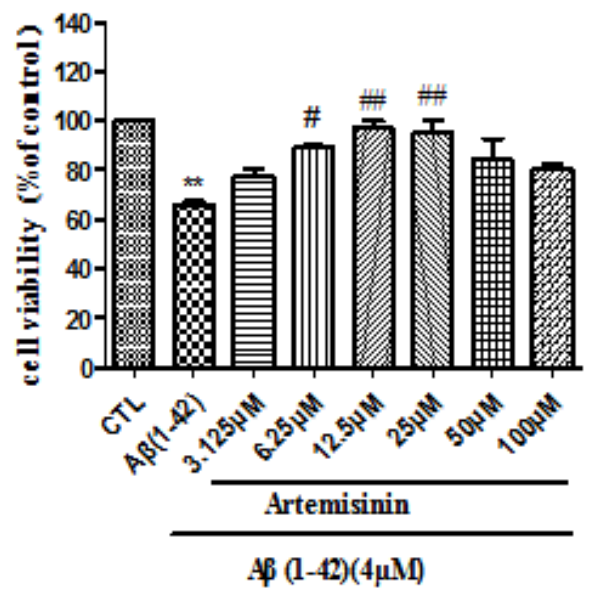

Figure 6. Artemisinin concentration- and time-dependently reversed the decrease in cell viability. (A) Chemical structure of ART. (B) The cytotoxicity of ART, cells were treated with ART $(3.125-200 \mu \mathrm{M})$ for $24 \mathrm{~h}$ and cell viability was measured using the MTT assay. (C) The cytotoxicity of A $\beta_{1-42}$. Cells were treated with $A \beta_{1-42}(0.5-8 \mu \mathrm{M})$ for $24 \mathrm{~h}$ and cell viability was measured using the MTT assay. (D) The effect of ART on cell viability. Cells were incubated with ART at indicated concentrations with or without $4 \mu \mathrm{M} \mathrm{A} \beta \beta_{-42}$ for another $24 \mathrm{~h}$ and cell viability was measured using the MTT assay. $* \mathrm{P}<0.05$ or $* * \mathrm{P}<0.01$, or $* * * \mathrm{P}<0.001$, CTL vs $\mathrm{A} \beta_{1-42} ;{ }^{\#} \mathrm{P}<0.05$ or ${ }^{\# \#} \mathrm{P}<0.01 \mathrm{~A} \beta_{1-42}$ vs $\mathrm{A} \beta_{1-42+} \mathrm{ART}$.

Artemisinin pretreatment attenuated $A_{1-42}$-induced apoptosis by reducing $R O S$ level and restored the mitochondrial membrane potential in SH-SY5Y cells

SH-SY5Y cells pretreated with or without $12.5 \mu \mathrm{M}$ ART for $2 h$ were further treated with $A \beta_{1-42}$ for $24 h$. The mitochondrial membrane potential $(\triangle \psi \mathrm{m})$ in SH-SY5Y cells was assessed by calculating the red/green fluorescent intensity ratio upon JC-1 staining. Cellular oxidative stress was assessed by CellROXs Deep Red Reagent. The results revealed that ART pretreatment significantly hindered the decline of $\Delta \psi \mathrm{m}$ and brought down the intracellular ROS production induced by $\mathrm{A} \beta_{1-42}$. Nuclei condensation was seen in SH-SY5Y cells after exposure to $4 \mu \mathrm{M} \mathrm{A} \beta_{1-42}$ by Hoechst 33342 staining assay. However, pre-treatment with $12.5 \mu \mathrm{M}$ ART significantly improved 
these changes (Fig. 7A - D). Cell apoptosis was further verified using flow cytometry for Annexin V-FITC/PIpositive cells and the results from these experiments indicated that $A \beta_{1-42}$ exposure markedly increased apoptosis in SH-SY5Y cells, while $12.5 \mu \mathrm{M}$ ART pretreatment significantly reduced the apoptosis caused by $A \beta_{1-42}$ (Fig. 7E and F). Western blotting revealed that ART pretreatment significantly reduced the expression level of Bax and increased the level of Bcl2 (Fig. $7 \mathrm{G}$ and $\mathrm{H})$.
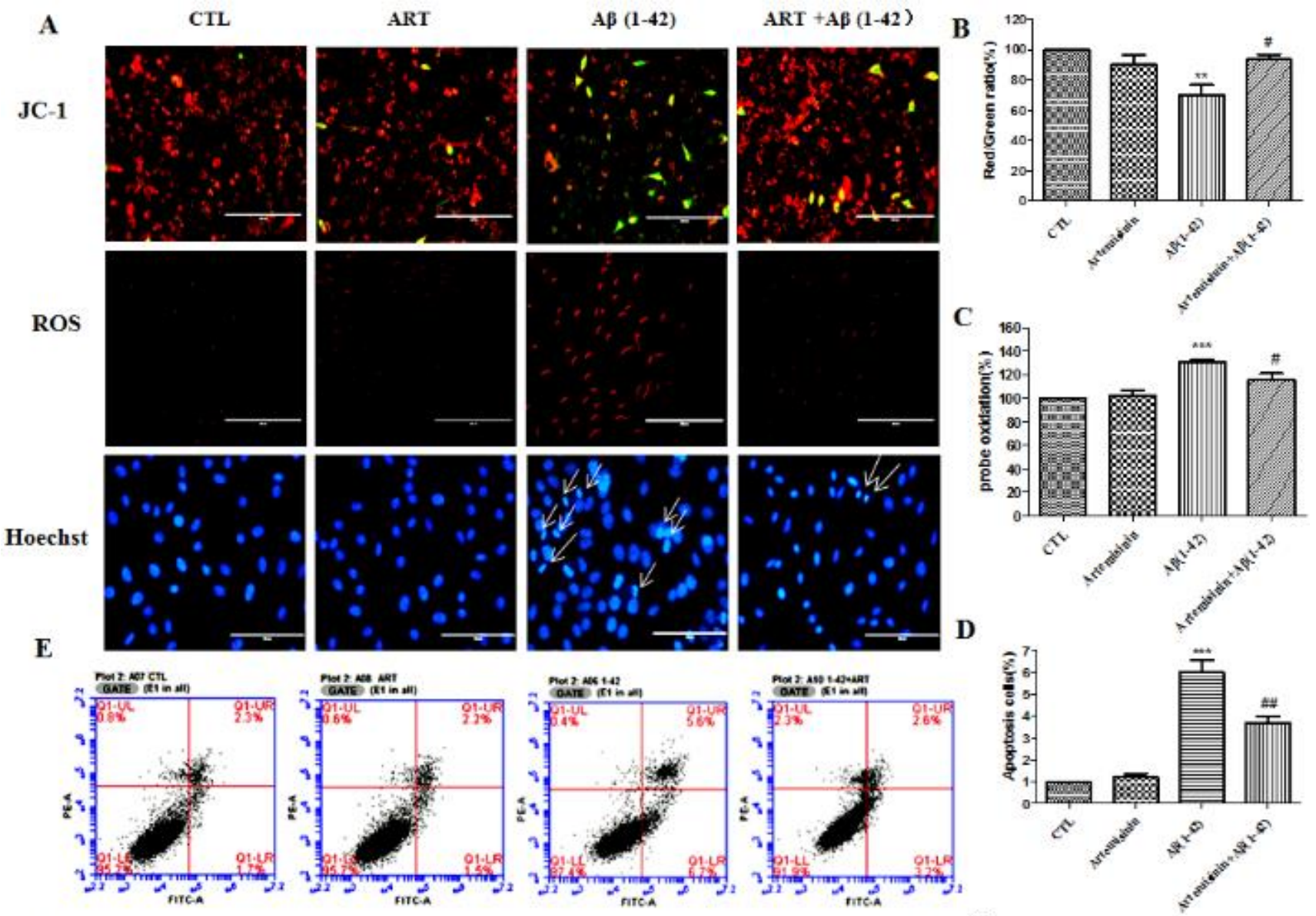

$\mathbf{F}$

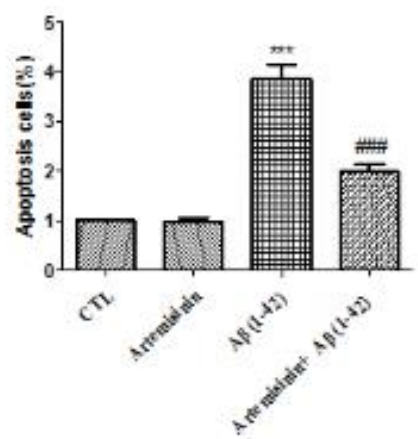

G

$\mathrm{Bd} 2$

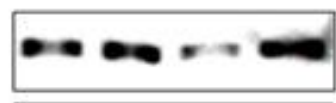

H

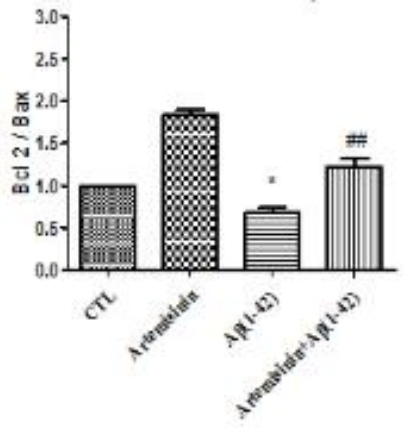

Figure 7. Artemisinin restored the mitochondrial membrane potential, and decreased ROS accumulation and reduced apoptosis induced by $\mathbf{A} \boldsymbol{\beta}_{1-42}$ in SH-SY5Y cells. (A) Cells were pretreated with $12.5 \mu \mathrm{M}$ ART for $120 \mathrm{~min}$ and then induced with or without $4 \mu \mathrm{M}$ $A \beta_{1-42}$ for a further $24 \mathrm{~h}$. The decline in the mitochondrial membrane potential was reflected by the shift of fluorescence from red to green indicated by JC-1. Intracellular ROS level was measured by the CellROXs Deep Red Reagent. Nuclear morphology measured by Hoechst staining (40x). (B-D) Statistical analysis results of JC-1, ROS and Hoechst staining in A. (E) Photographs of representative cultures measured by Flow cytometry. (F) Statistical analysis results of Flow cytometry in E. (G) Expression of Bax, Bcl-2, and GAPDH were detected with Western blotting. (H) Quantification of representative protein band from Western blotting in $\mathrm{G}$. ${ }^{*} \mathrm{P}<0.05$ or ** $\mathrm{P}<0.01$, or $* * * \mathrm{P}<0.001, \mathrm{CTL}$ vs $\mathrm{A} \beta 1-42 ;{ }^{\#} \mathrm{P}<0.05$ or ${ }^{\# \#} \mathrm{P}<0.01$ or ${ }^{\# \# \#} \mathrm{P}<0.001 \mathrm{~A} \beta_{1-42}$ vs $\mathrm{A} \beta \beta_{1-42+} \mathrm{ART}$. 


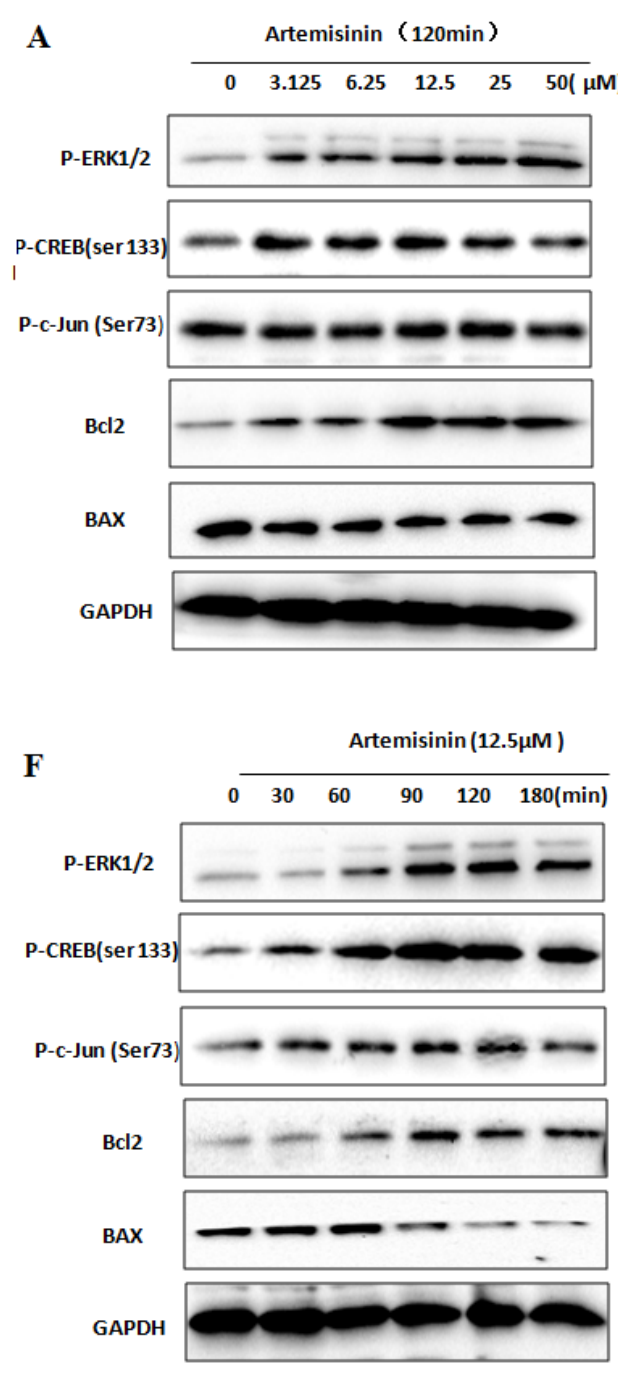

\section{B \\ D}
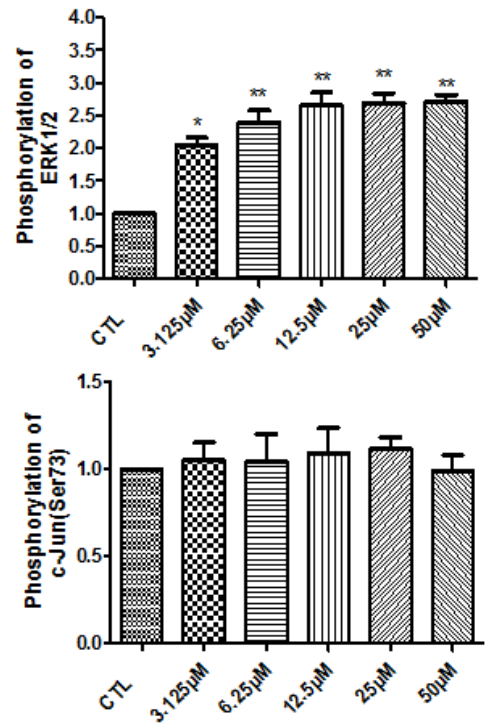

G
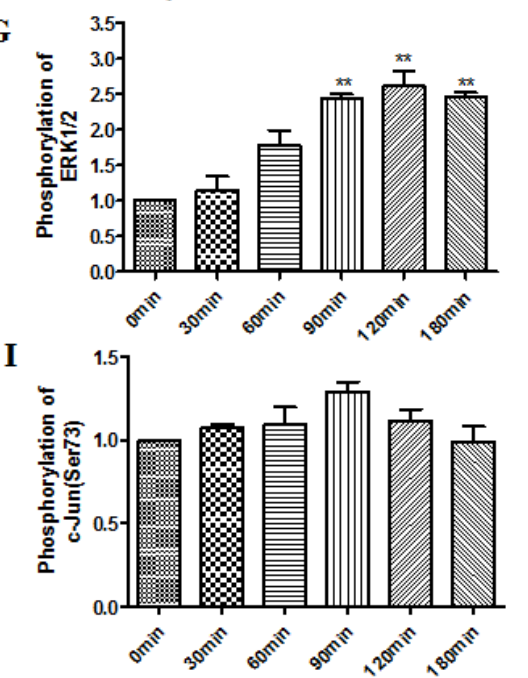

C

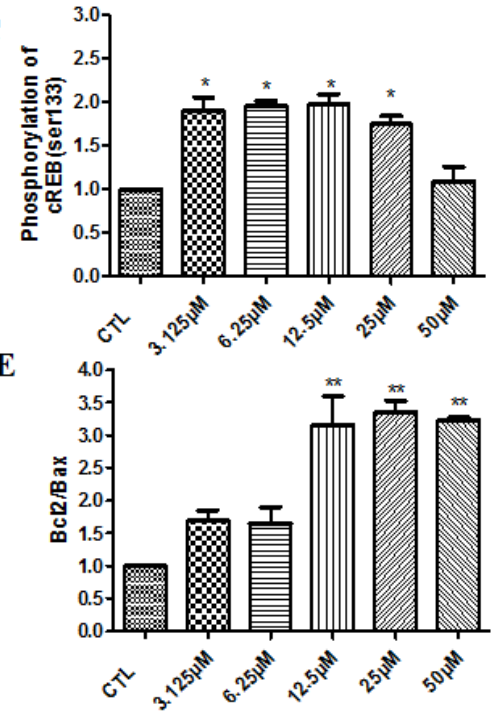

H

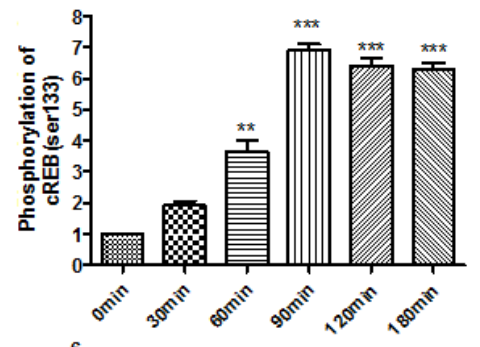

$\mathbf{J}$

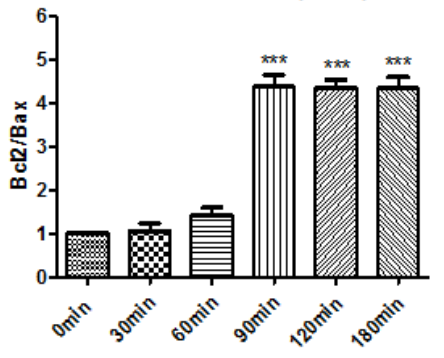

Figure 8. Artemisinin increased phosphorylation of ERK and CREB (ser133) in SH-SY5Y cells. (A) The SH-SY5Y cells were treated with ART for $120 \mathrm{~min}$ at different concentrations $(3.15,6.25,12.5,25$ and $50 \mu \mathrm{M})$ and the expression of P-ERK1/2, p-CREB, P-C-Jun, Bcl2, Bax and GAPDH were detected by Western blot. (B-E) Statistical analysis results of A. (F) The SH-SY5Y cells were treated with ART for different times $(0,30,60,90,120$ and $180 \mathrm{~min})$ at $12.5 \mu \mathrm{M}$ and the expression of P-ERK1/2, p-CREB, P-C-Jun, $\mathrm{Bcl} 2$, Bax and GAPDH were detected by Western blot. (G-J) Statistical analysis results of $\mathrm{F}$. $* \mathrm{P}<0.05$ or $* * \mathrm{P}<0.01$, or $* * * \mathrm{P}<0.001$.

ERK involved the protective effects of artemisinin in $\mathrm{SH}$ SY5Y cells

Figure $5 \mathrm{~F}$ have shown that ART stimulated the activation of ERK/CREB pathway in 3xTg mice brain, so we used western blot to find out whether the ERK/CREB signaling pathway is regulated by ART in SH-SY5Y cells also. Results showed that within $180 \mathrm{~min}$, ART gradually raised the phosphorylation intensity of ERK1/2 and CREB in SH-SY5Y cells in a time- and dose- dependent manner. But we have not found that ART has a significant change in phosphorylation intensity of c-Jun. These results indicated that ART might be activating ERK/CREB survival signaling. Similarly, a time- and dose- dependent increase of $\mathrm{Bcl}-2 / \mathrm{Bax}$ ratio upon ART treatment was observed by Western blot (Fig. 8A-J). Taken together, our results demonstrated that artemisinin reduced apoptosis through activation of ERK/CREB/Bcl2 axis in SH-SY5Y cells.

To further confirm whether ERK is associated with the survival promoting effect of ART on cell apoptosis induced by $A \beta_{1-42}$, we pretreated the cells with PD98059 (a specific inhibitor of ERK) for $60 \mathrm{~min}$ and then the cells were treated with ART for $2 \mathrm{~h}$ followed by $A \beta_{1-42}$ for another 24h. TUNEL staining, Flow cytometry and MTT results showed that pretreatment of PD98059 blocked the protective effects of ART (Fig. 9A-E). Otherwise, the recovery of the mitochondrial membrane potential and 
decreased the intracellular ROS were reversed after PD98059 added (Supplementary Fig. 1). Similar results were obtained from Western blot which showed that ART was not able to suppress the expression of apoptosis regulators: Cytochrome C, cleaved caspase-9, cleaved caspase 3 and increased the expression of p-CREB, Bcl2/Bax ratio in the presence of the ERK pathway inhibitor PD98059 (Fig. 9F-J), which suggested that ERK/CREB signaling is involved in the protective effects of ART against $A \beta_{1-42}$ induced toxicity.
$\mathbf{A}$
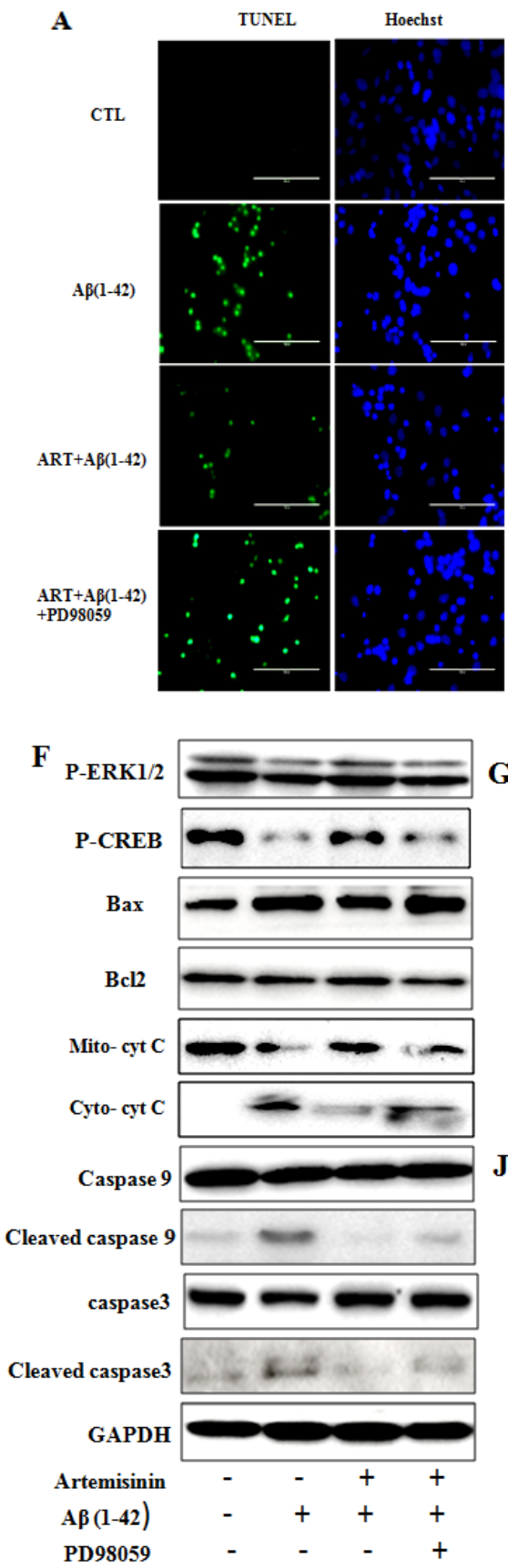

B

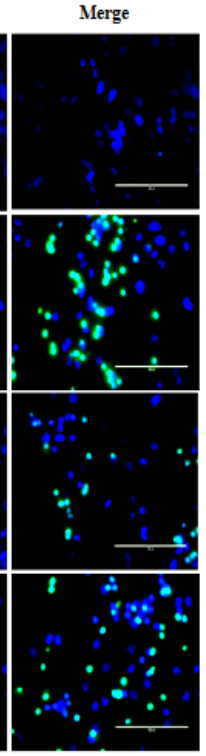

D
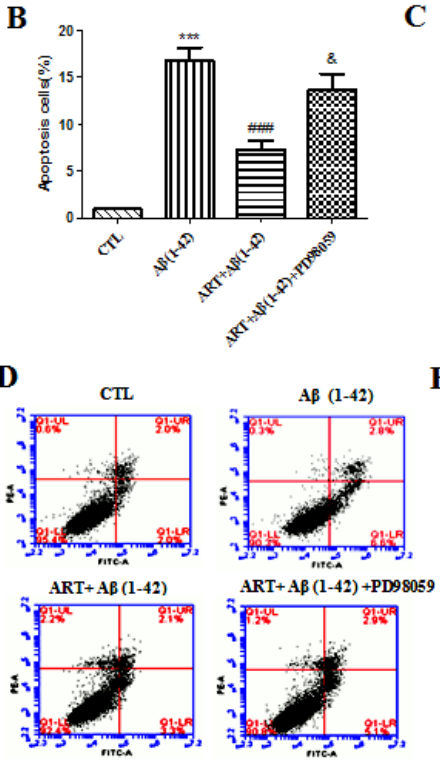

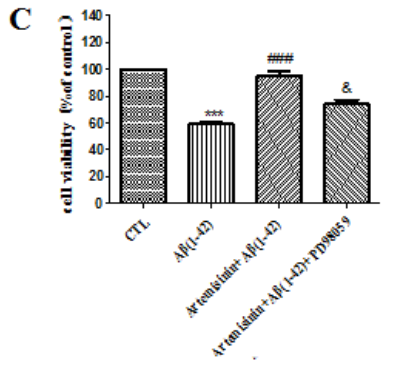

$\mathbf{E}$

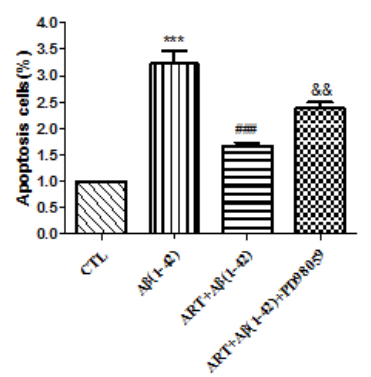

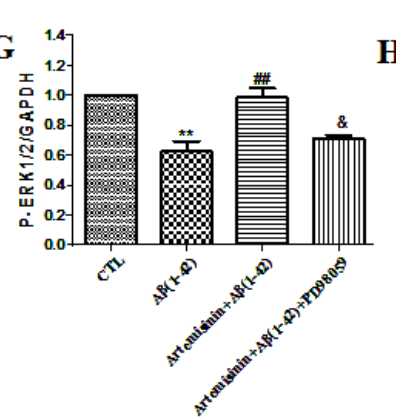
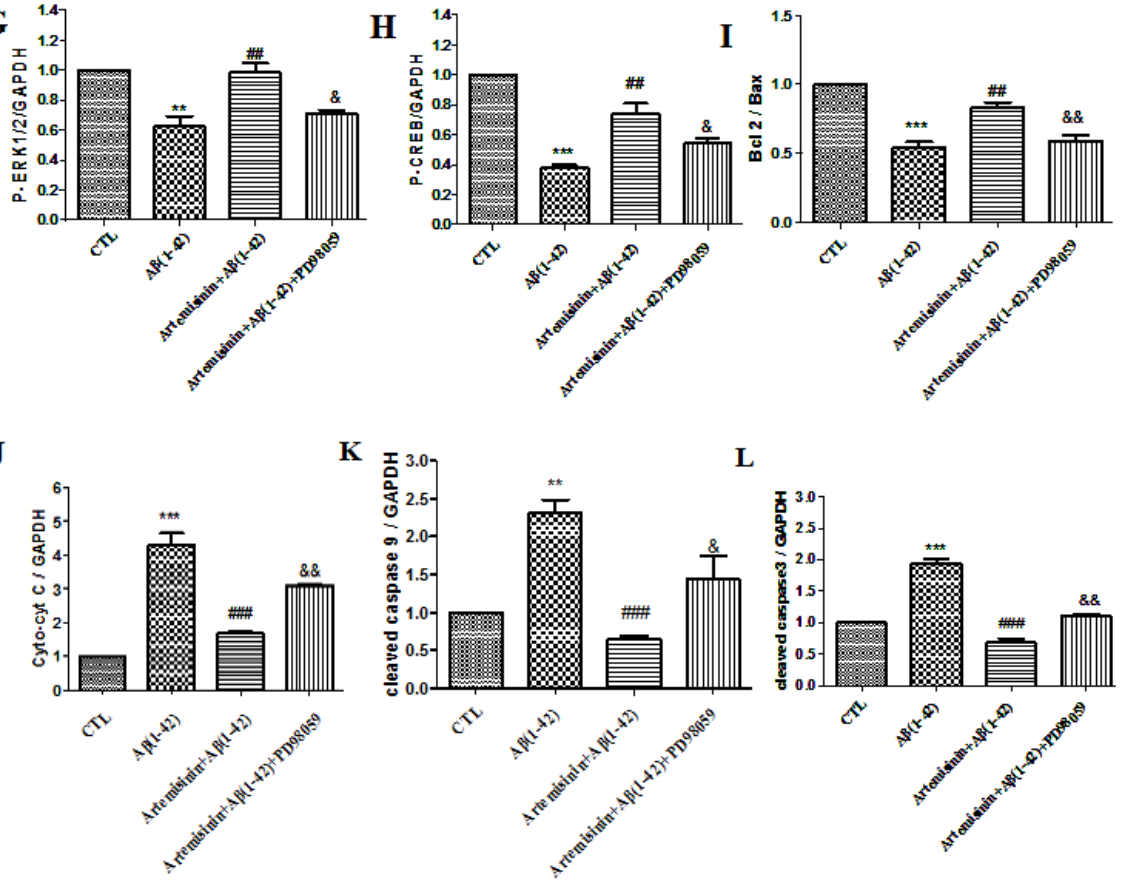

$\mathbf{L}$

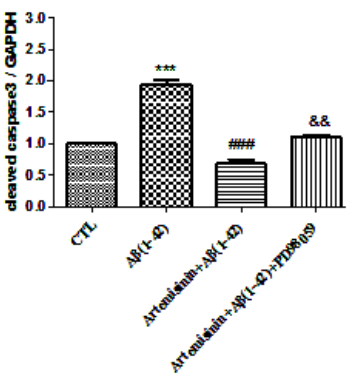

Figure 9. ERK/CREB pathway mediated the protective effects of artemisinin in SH-SY5Y cells. (A-B) Cells, pretreated with 25 $\mu \mathrm{M}$ PD98059 (ERK inhibitor) for $60 \mathrm{~min}$, were incubated with $4 \mu \mathrm{M} \mathrm{A} \beta_{1-42}$ in the presence or absence of $12.5 \mu \mathrm{M}$ ART. Apoptosis was measured by Tunel staining (40x). (C) Cell viability was measured by MTT assay. (D-E) Apoptosis was measured by Flow cytometry. (F) P-ERK1/2, P-CREB, Bax, Bcl2, Cytochrome C, cleaved caspase9 and cleaved caspase3 were measured by Western blot. (G-L) Statistical analysis results of P-ERK1/2, P-CREB, Bax, Bcl2, Cytochrome C, cleaved caspase9, cleaved caspase3. *: Difference between the $A \beta_{1-42}$ group and WT groups; \#: Difference between the $A \beta_{1-42}$ and other groups; $\&$ : Difference between the $A R T+A \beta_{1-42}$ and other groups; ${ }^{* * \mathrm{P}}<0.01,{ }^{* * *} \mathrm{P}<0.001,{ }^{\#} \mathrm{P}<0.01,{ }^{\# \#} \mathrm{P}<0.001,{ }^{\&} \mathrm{P}<0.05,{ }^{\& \&} \mathrm{P}<0.01$. 


\section{DISCUSSION}

$\mathrm{AD}$ is one of the neurodegenerative disorders that affects older population and is clinically characterized by progressive loss of memory along with decline in multiple cognitive abilities [42, 43]. A $\beta$ accumulation plays a crucial role in $\mathrm{AD}$ which could cause a number of important pathological changes such as: oxidative stress, inflammation, defects and alterations in cholinergic neurons, synaptic deficit, proliferation of reactive astrocytes, and neuronal death $[44,45]$. As the multifactorial nature of $\mathrm{AD}$, the search for Chinese herbal compounds with a wide spectrum of neuroprotective activities, hold very encouraging future for the treatment of AD [46]. ART, widely used in the clinic as an antimalarial drug, has exhibited neuroprotective effects in various neuronal cells $[47,48]$. However, the mechanism is still not clear and protective effects of ART on cognitive impairment and pathology in-vivo are not well known so far. $3 \times T$ mice develop $A \beta$ and tau pathology, as well as neuroinflammation and cognitive deficits. In order to check all the pathological features of $\mathrm{AD}$, we chose oneyear-old mice to perform our experiments. In this study, we demonstrated preclinical in-vitro (SH-SY5Y) and invivo ( $3 \times \mathrm{XTg})$ neuroprotective correlations (IVIVC) for ART.

It is clear from Morris water maze results, that, ART can lessen the escape latency and path length of $3 \times \mathrm{Tg}$ mice, suggesting that ART could recover the learning and spatial memory capacity during $\mathrm{AD}$. The hallmarks of $\mathrm{AD}$ are extracellular accumulation of $A \beta$ and intracellular NFT $[49,50]$. Deposition of $A \beta$ and Tau in brain is the primary characteristic as well as drug target for the diagnostic and therapeutic intervention of $\mathrm{AD}[51]$. $\mathrm{A} \beta$ accumulates and deposits into soluble fibrils, oligomers, and senile plaques, which is the main pathological reason for synaptic malfunction and neuronal network disruptions, ultimately causing massive atrophy of the brain and cognitive deterioration in $\mathrm{AD}$ patients and $3 \times \mathrm{Tg}$ mice[52, 53]. Our result showed that ART treatment significantly reduced the rising numbers of senile plaques in the cerebral cortex and hippocampus of $3 \times \mathrm{Tg}$ mice.

Results from the study on transgenic mice model for Amyloid precursor protein have shown that $A \beta$ can continue to activate inflammatory response, including excessive activation of glial cells and activation of cytokines[54]. GFAP is a primary intermediate filament protein which is specific to astrocytes. The increased GFAP is usually considered as an indicator of gliosis or a comparatively slow-developing index of neural damage linked with old age and the onset of AD pathology[55, 56]. We found that the GFAP activity was significantly decreased with the treatment of ART in $3 \times \mathrm{Tg}$ mice. Microglia (MG) is the main immune cell of the CNS and widely distributed in the brain. Overactivated microglia will release a large number of pro-inflammatory and other neurotoxic substances which will cause varying degrees of damage to neurons. Our result showed that ART treatment significantly improved microglia morphology in 3xTg mice. In addition, ART reduced the release of main inflammatory factors, further supporting its antiinflammatory effects.

Previous reports have suggested that mitochondrial dysfunction, oxidative stress, and apoptosis may play important role in the overall process of $\mathrm{AD}$. $\mathrm{A} \beta$ can result in the decrease in the $\triangle \psi \mathrm{m}$ of atrocities via activation of NADPH oxidase, causing oxidative stress and leading to neuronal death $[57,58]$. A $\beta$ also damages mitochondria causing dysfunction of mitochondrial complexes I and IV, which result in reactive oxygen species (ROS) overproduction and adenosine triphosphate (ATP) depletion. ROS increase in turn leads to mitochondrial permeability transition pore (MPTP) open which increases mitochondrial damage [59, 60]. Damaged mitochondria release Cytochrome $\mathrm{C}$, further activating the caspase family and triggering apoptosis. The Caspase family exerts a crucial role in mediating apoptosis, where Caspase- 3 is the main executive molecule functioning in multiple apoptotic signaling pathways. Caspase- 3 usually exists in the cytoplasm in the form of zymogens (32KD), which is activated upon apoptosis, and cleaves the corresponding cytoplasm nucleus substrate, eventually leading to apoptosis. $\mathrm{Bcl} 2 / \mathrm{Bax}$ family is a major mitochondrial protein. The ratio of $\mathrm{Bcl} 2 / \mathrm{Bax}$ is a "molecular switch" that initiates apoptosis [61-63]. In present study, the apoptosis regulator Cytochrome C, caspase-9, caspase-3 activity was inevitably decreased and ratio of Bcl2/Bax was slightly increased with ART treatment in 3xTg mice and SH-SY5Y cells. Similar results were obtained by TUNEL staining in the brain of $3 \times T g$ mice. In addition, ART treatment of A $\beta$-induced cell death reduced the production of ROS, corrected mitochondrial membrane potential in SH-SY5Y cells.

ERK pathway plays central role in the initiation and regulation of many accelerated cellular processes such as proliferation, differentiation, and survival [64]. It has been shown that neuroprotection in AD could result from the decreasing level of oxidative stress mediated by ERK activation [65]. In present study, the rise in ERK1/2 phosphorylation level, after treatment with ART, was seen both in 3xTg mice and SH-SY5Y cells. After ART intervention, the expression of Bax was brought down, while the expression level of $\mathrm{Bcl} 2$ was enhanced significantly. Furthermore, our results demonstrated that

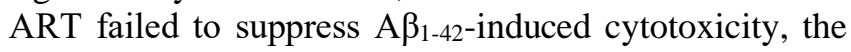
increase of $\mathrm{Bcl} 2 / \mathrm{Bax}$ ratio and caspase 3 activity in the presence of PD98059 which is an ERK inhibitor. According to these results, ART regulated the protective 
effects against $A \beta_{1-42}$-induced damage by ERK/CREB pathway. Thus the inhibition of ERK could play important role in therapeutics and pathophysiological of AD.

Our study suggests that ART can protect neuronal cells from $\mathrm{A} \beta_{1-42}$-induced cell damage in-vivo and in-vitro of $\mathrm{AD}$ models via, at least in part, the activation of the ERK/CREB pathway and inhibition of apoptosis pathway. Furthermore, ART can alleviate the learning and spatial memory destruction in $3 \times \mathrm{Tg}$ mice. At the same time, ART reduced the $A \beta$ and Tau deposition and also reduced the inflammatory response in the brain of $3 \times \mathrm{Tg}$ mice (Fig. 10). Therefore, therapeutic intervention with ART could be useful for AD patients.

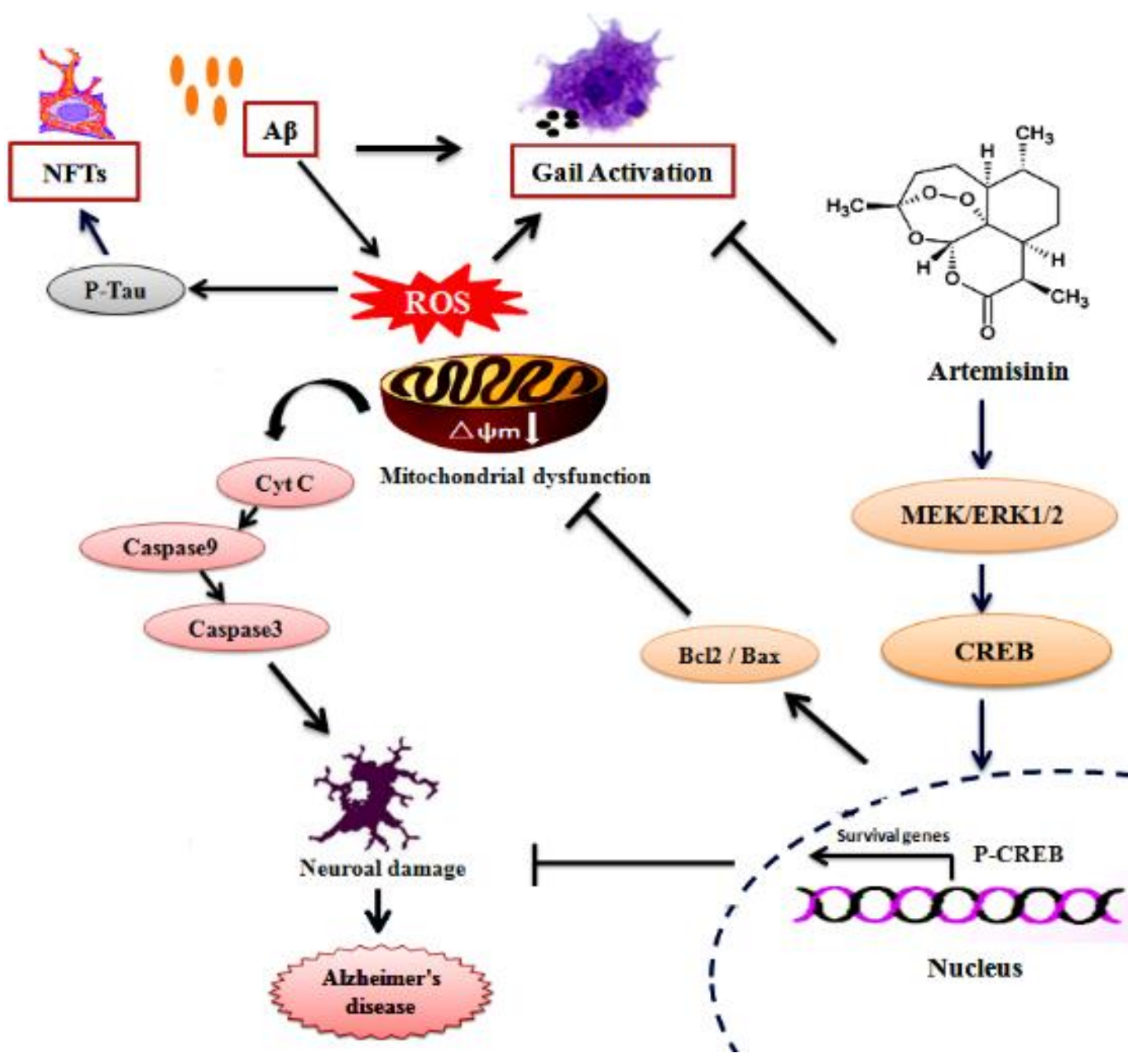

Figure 10. The possible mechanism of artemisinin mediated neuroprotection against $\mathbf{A}_{1-42}$-induced injury in neuronal cells and in 3xTg mice. Artemisinin stimulated ERK1/2 phosphorylation in neuronal cells and the brain of 3xTg mice, which results in activation of CREB/Bcl-2 survival pathway and inhibit apoptosis pathway. This process may reduce oxidative stress, correction of mitochondrial dysfunction. In addition, artemisinin also reduced the inflammatory release and reduced the deposition of amyloid plaques and neurofibrillary tangles.

\section{Acknowledgements}

This research was supported by National Natural Science Foundation of China (No. 31771128). Science and Technology Development Fund (FDCT) of Macao (FDCT 016/2016/A1) and the MYRG2016-00052-FHS and MYRG2018-00134-FHS from the University of
Macau. We are grateful to UM-FHS and core facilities for equipment and administrative support for this study.

\section{Competing interests}

Authors declare that no conflict of interest exists. 


\section{Supplementary Materials}

The Supplementary data can be found online at: www.aginganddisease.org/EN/10.14336/AD.2019.0813.

\section{References}

[1] Liu M, Guo H, Li C, Wang D, Wu J, Wang C, et al. (2015). Cognitive improvement of compound danshen in an Abeta25-35 peptide-induced rat model of Alzheimer's disease. BMC Complement Altern Med, 15:382.

[2] Wei C, Zhang W, Zhou Q, Zhao C, Du Y, Yan Q, et al. (2016). Mithramycin A Alleviates Cognitive Deficits and Reduces Neuropathology in a Transgenic Mouse Model of Alzheimer's Disease. Neurochem Res, 41:1924-1938.

[3] Behl C, Ziegler C (2017). Beyond Amyloid - Widening the View on Alzheimer's Disease. J Neurochem, 143:394-395.

[4] Hatashita S, Wakebe D (2017). Amyloid-beta Deposition and Long-Term Progression in Mild Cognitive Impairment due to Alzheimer's Disease Defined with Amyloid PET Imaging. J Alzheimers Dis, 57:765-773.

[5] Choo XY, Alukaidey L, White AR, Grubman A (2013). Neuroinflammation and copper in Alzheimer's disease. Int J Alzheimers Dis, 2013:145345.

[6] Maccioni RB, Farias G, Morales I, Navarrete L (2010). The revitalized tau hypothesis on Alzheimer's disease. Arch Med Res, 41:226-231.

[7] Butterfield DA, Swomley AM, Sultana R (2013). Amyloid beta-peptide (1-42)-induced oxidative stress in Alzheimer disease: importance in disease pathogenesis and progression. Antioxid Redox Signal, 19:823-835.

[8] Wagner LK, Gilling KE, Schormann E, Kloetzel PM, Heppner FL, Kruger E, et al. (2017). Immunoproteasome deficiency alters microglial cytokine response and improves cognitive deficits in Alzheimer's disease-like APPPS1 mice. Acta Neuropathol Commun, 5:52.

[9] Branca C, Ferreira E, Nguyen TV, Doyle K, Caccamo A, Oddo S (2017). Genetic reduction of Nrf2 exacerbates cognitive deficits in a mouse model of Alzheimer's disease. Hum Mol Genet, 26:4823-4835.

[10] Aliev G (2011). Oxidative stress induced-metabolic imbalance, mitochondrial failure, and cellular hypoperfusion as primary pathogenetic factors for the development of Alzheimer disease which can be used as a alternate and successful drug treatment strategy: past, present and future. CNS Neurol Disord Drug Targets, 10:147-148.

[11] Aliev G, Obrenovich ME, Smith MA, Perry G (2003). Hypoperfusion, Mitochondria Failure, Oxidative Stress, and Alzheimer Disease. J Biomed Biotechnol, 2003:162163.

[12] Candore G, Bulati M, Caruso C, Castiglia L, ColonnaRomano G, Di Bona D, et al. (2010). Inflammation, cytokines, immune response, apolipoprotein E, cholesterol, and oxidative stress in Alzheimer disease: therapeutic implications. Rejuvenation Res, 13:301-313.

[13] Cai Z, Hussain MD, Yan LJ (2014). Microglia, neuroinflammation, and beta-amyloid protein in
Alzheimer's disease. Int J Neurosci, 124:307-321.

[14] Zhang M, Wang Y, Qian F, Li P, Xu X (2016). Hypericin inhibits oligomeric amyloid beta42-induced inflammation response in microglia and ameliorates cognitive deficits in an amyloid beta injection mouse model of Alzheimer's disease by suppressing MKL1. Biochem Biophys Res Commun, 481:71-76.

[15] Zhou X, Li Y, Shi X, Ma C (2016). An overview on therapeutics attenuating amyloid beta level in Alzheimer's disease: targeting neurotransmission, inflammation, oxidative stress and enhanced cholesterol levels. Am J Transl Res, 8:246-269.

[16] Wu X, Kosaraju J, Tam KY (2018). Antineuroinflammatory effects of SLOH in Abeta-induced BV-2 microglial cells and 3xTg-AD mice involve the inhibition of GSK-3beta. Neurosci Lett, 687:207-215.

[17] Zuo S, Li Q, Liu X, Feng H, Chen Y (2016). The Potential Therapeutic Effects of Artesunate on Stroke and Other Central Nervous System Diseases. Biomed Res Int, 2016:1489050.

[18] Alzheimer's A (2016). 2016 Alzheimer's disease facts and figures. Alzheimers Dement, 12:459-509.

[19] Wu X, Kosaraju J, Zhou W, Tam KY (2018). SLOH, a carbazole-based fluorophore, mitigates neuropathology and behavioral impairment in the triple-transgenic mouse model of Alzheimer's disease. Neuropharmacology, 131:351-363.

[20] Collins JM, King AE, Woodhouse A, Kirkcaldie MT, Vickers JC (2015). The effect of focal brain injury on beta-amyloid plaque deposition, inflammation and synapses in the APP/PS1 mouse model of Alzheimer's disease. Exp Neurol, 267:219-229.

[21] Schmuck G, Roehrdanz E, Haynes RK, Kahl R (2002). Neurotoxic mode of action of artemisinin. Antimicrobial agents and chemotherapy, 46:821-827.

[22] Zeng Z, Xu J, Zheng W (2017). Artemisinin protects PC12 cells against $\beta$-amyloid-induced apoptosis through activation of the ERK1/2 signaling pathway. Redox biology, 12:625-633.

[23] Zheng W, Chong C-M, Wang H, Zhou X, Zhang L, Wang $\mathrm{R}$, et al. (2016). Artemisinin conferred ERK mediated neuroprotection to $\mathrm{PC} 12$ cells and cortical neurons exposed to sodium nitroprusside-induced oxidative insult. Free Radic Biol Med, 97:158-167

[24] Shi JQ, Zhang CC, Sun XL, Cheng XX, Wang JB, Zhang $\mathrm{YD}$, et al. (2013). Antimalarial drug artemisinin extenuates amyloidogenesis and neuroinflammation in APPswe/PS1dE9 transgenic mice via inhibition of nuclear factor-kappaB and NLRP3 inflammasome activation. CNS Neurosci Ther, 19:262-268.

[25] Belfiore R, Rodin A, Ferreira E, Velazquez R, Branca C, Caccamo A, et al. (2019). Temporal and regional progression of Alzheimer's disease-like pathology in 3xTg-AD mice. Aging Cell, 18:e12873.

[26] Resende R, Moreira PI, Proenca T, Deshpande A, Busciglio J, Pereira C, et al. (2008). Brain oxidative stress in a triple-transgenic mouse model of Alzheimer disease. Free Radic Biol Med, 44:2051-2057.

[27] Gimenez-Llort L, Blazquez G, Canete T, Johansson B, Oddo S, Tobena A, et al. (2007). Modeling behavioral 
and neuronal symptoms of Alzheimer's disease in mice: a role for intraneuronal amyloid. Neurosci Biobehav Rev, 31:125-147.

[28] Jin N, Zhu H, Liang X, Huang W, Xie Q, Xiao P, et al. (2017). Sodium selenate activated Wnt/beta-catenin signaling and repressed amyloid-beta formation in a triple transgenic mouse model of Alzheimer's disease. Exp Neurol, 297:36-49.

[29] Li T, Jiao JJ, Holscher C, Wu MN, Zhang J, Tong JQ, et al. (2018). A novel GLP-1/GIP/Gcg triagonist reduces cognitive deficits and pathology in the $3 \times \mathrm{Tg}$ mouse model of Alzheimer's disease. Hippocampus, 28:358372.

[30] Sah SK, Lee C, Jang JH, Park GH (2017). Effect of highfat diet on cognitive impairment in triple-transgenic mice model of Alzheimer's disease. Biochem Biophys Res Commun, 493:731-736.

[31] Baazaoui N, Flory M, Iqbal K (2017). Synaptic Compensation as a Probable Cause of Prolonged Mild Cognitive Impairment in Alzheimer's Disease: Implications from a Transgenic Mouse Model of the Disease. J Alzheimers Dis, 56:1385-1401.

[32] Xu TT, Zhang Y, He JY, Luo D, Luo Y, Wang YJ, et al. (2018). Bajijiasu Ameliorates beta-Amyloid-Triggered Endoplasmic Reticulum Stress and Related Pathologies in an Alzheimer's Disease Model. Cell Physiol Biochem, 46:107-117.

[33] Zhang H, Ren NT, Zhou FQ, Li J, Lei W, Liu N, et al. (2016). Effects of Hindlimb Unweighting on MBP and GDNF Expression and Morphology in Rat Dorsal Root Ganglia Neurons. Neurochem Res, 41:2433-2442.

[34] Chen C, Li B, Cheng G, Yang X, Zhao N, Shi R (2018). Amentoflavone Ameliorates Abeta1-42-Induced Memory Deficits and Oxidative Stress in Cellular and Rat Model. Neurochem Res, 43:857-868.

[35] Yan F, Wang H, Gao Y, Xu J, Zheng W (2017). Artemisinin Protects Retinal Neuronal Cells against Oxidative Stress and Restores Rat Retinal Physiological Function from Light Exposed Damage. ACS Chem Neurosci, 8:1713-1723.

[36] Dimauro I, Pearson T, Caporossi D, Jackson MJ (2012). A simple protocol for the subcellular fractionation of skeletal muscle cells and tissue. BMC Res Notes, 5:513.

[37] Zhang H, Wang P, Xue Y, Liu L, Li Z, Liu Y (2018). Allicin ameliorates cognitive impairment in APP/PS1 mice via Suppressing oxidative stress by Blocking JNK Signaling Pathways. Tissue Cell, 50:89-95.

[38] Cheng S, LeBlanc KJ, Li L (2014). Triptolide preserves cognitive function and reduces neuropathology in a mouse model of Alzheimer's disease. PLoS One, 9:e108845.

[39] Philippens IH, Ormel PR, Baarends G, Johansson M, Remarque EJ, Doverskog M (2017). Acceleration of Amyloidosis by Inflammation in the Amyloid-Beta Marmoset Monkey Model of Alzheimer's Disease. J Alzheimers Dis, 55:101-113.

[40] Ghanim H, Monte SV, Sia CL, Abuaysheh S, Green K, Caruana JA, et al. (2012). Reduction in inflammation and the expression of amyloid precursor protein and other proteins related to Alzheimer's disease following gastric bypass surgery. J Clin Endocrinol Metab, 97:E1197-1201.

[41] Sabogal-Guaqueta AM, Munoz-Manco JI, RamirezPineda JR, Lamprea-Rodriguez M, Osorio E, CardonaGomez GP (2015). The flavonoid quercetin ameliorates Alzheimer's disease pathology and protects cognitive and emotional function in aged triple transgenic Alzheimer's disease model mice. Neuropharmacology, 93:134-145.

[42] Fu AK, Hung KW, Yuen MY, Zhou X, Mak DS, Chan IC, et al. (2016). IL-33 ameliorates Alzheimer's disease-like pathology and cognitive decline. Proc Natl Acad Sci U S A, 113:E2705-2713.

[43] Martinez-Coria H, Yeung ST, Ager RR, Rodriguez-Ortiz CJ, Baglietto-Vargas D, LaFerla FM (2015). Repeated cognitive stimulation alleviates memory impairments in an Alzheimer's disease mouse model. Brain Res Bull, 117:10-15.

[44] Parbo P, Ismail R, Hansen KV, Amidi A, Marup FH, Gottrup H, et al. (2017). Brain inflammation accompanies amyloid in the majority of mild cognitive impairment cases due to Alzheimer's disease. Brain, 140:2002-2011.

[45] Khan A, Vaibhav K, Javed H, Tabassum R, Ahmed ME, Khan MM, et al. (2014). 1,8-cineole (eucalyptol) mitigates inflammation in amyloid Beta toxicated PC12 cells: relevance to Alzheimer's disease. Neurochem Res, 39:344-352.

[46] Bignante EA, Ponce NE, Heredia F, Musso J, Krawczyk MC, Millan J, et al. (2018). APP/Go protein Gbetagamma-complex signaling mediates Abeta degeneration and cognitive impairment in Alzheimer's disease models. Neurobiol Aging, 64:44-57.

[47] Lin S-P, Li W, Liu R, Yang S (2018). Artemisinin Prevents Glutamate-Induced Neuronal Cell Death Via Akt Pathway Activation. Frontiers in cellular neuroscience, 12:108.

[48] Chong C-M, Zheng W (2016). Artemisinin protects human retinal pigment epithelial cells from hydrogen peroxide-induced oxidative damage through activation of ERK/CREB signaling. Redox biology, 9:50-56.

[49] Oliveira LT, Louzada PR, de Mello FG, Ferreira ST (2011). Amyloid-beta decreases nitric oxide production in cultured retinal neurons: a possible mechanism for synaptic dysfunction in Alzheimer's disease? Neurochem Res, 36:163-169.

[50] Wang X, Song R, Lu W, Liu Z, Wang L, Zhu X, et al. (2017). YXQN Reduces Alzheimer's Disease-Like Pathology and Cognitive Decline in APPswePS1dE9 Transgenic Mice. Front Aging Neurosci, 9:157.

[51] Cherry JD, Liu B, Frost JL, Lemere CA, Williams JP, Olschowka JA, et al. (2012). Galactic cosmic radiation leads to cognitive impairment and increased abeta plaque accumulation in a mouse model of Alzheimer's disease. PLoS One, 7:e53275.

[52] Chun H, Lee CJ (2018). Reactive astrocytes in Alzheimer's disease: A double-edged sword. Neurosci Res, 126:44-52.

[53] Kimura A, Takemura M, Saito K, Yoshikura N, Hayashi Y, Harada N, et al. (2017). Comparison of cerebrospinal 
fluid profiles in Alzheimer's disease with multiple cerebral microbleeds and cerebral amyloid angiopathyrelated inflammation. J Neurol, 264:373-381.

[54] Gold M, El Khoury J (2015). beta-amyloid, microglia, and the inflammasome in Alzheimer's disease. Semin Immunopathol, 37:607-611.

[55] Lian H, Litvinchuk A, Chiang AC, Aithmitti N, Jankowsky JL, Zheng H (2016). Astrocyte-Microglia Cross Talk through Complement Activation Modulates Amyloid Pathology in Mouse Models of Alzheimer's Disease. J Neurosci, 36:577-589.

[56] Xie J, Wang H, Lin T, Bi B (2017). Microglia-Synapse Pathways: Promising Therapeutic Strategy for Alzheimer's Disease. Biomed Res Int, 2017:2986460.

[57] Guo C, Sun L, Chen X, Zhang D (2013). Oxidative stress, mitochondrial damage and neurodegenerative diseases. Neural Regen Res, 8:2003-2014.

[58] Mancuso M, Calsolaro V, Orsucci D, Carlesi C, Choub A, Piazza S, et al. (2009). Mitochondria, cognitive impairment, and Alzheimer's disease. Int J Alzheimers Dis, 2009.

[59] Ali SF, David SN, Newport GD, Cadet JL, Slikker W, Jr. (1994). MPTP-induced oxidative stress and neurotoxicity are age-dependent: evidence from measures of reactive oxygen species and striatal dopamine levels. Synapse, 18:27-34.
[60] Su Y, Duan J, Ying Z, Hou Y, Zhang Y, Wang R, et al. (2013). Increased vulnerability of parkin knock down PC12 cells to hydrogen peroxide toxicity: the role of salsolinol and NM-salsolinol. Neuroscience, 233:72-85.

[61] Lindenboim L, Haviv R, Stein R (1998). Bcl-xL inhibits different apoptotic pathways in rat PC12 cells. Neurosci Lett, 253:37-40.

[62] Deng G, Su JH, Ivins KJ, Van Houten B, Cotman CW (1999). Bcl-2 facilitates recovery from DNA damage after oxidative stress. Exp Neurol, 159:309-318.

[63] Vucicevic K, Jakovljevic V, Colovic N, Tosic N, Kostic T, Glumac I, et al. (2016). Association of Bax Expression and Bcl2/Bax Ratio with Clinical and Molecular Prognostic Markers in Chronic Lymphocytic Leukemia. J Med Biochem, 35:150-157.

[64] Ogura Y, Sato K, Kawashima K, Kobayashi N, Imura S, Fujino K, et al. (2014). Subtoxic levels of hydrogen peroxide induce brain-derived neurotrophic factor expression to protect PC12 cells. BMC Res Notes, 7:840.

[65] Kwon SH, Kim JA, Hong SI, Jung YH, Kim HC, Lee SY, et al. (2011). Loganin protects against hydrogen peroxide-induced apoptosis by inhibiting phosphorylation of JNK, p38, and ERK 1/2 MAPKs in SH-SY5Y cells. Neurochem Int, 58:533-541. 